Portland State University

PDXScholar

\title{
Toward a test for ethnocentrism and ethnorelativism based upon reference group orientation
}

James C. Mayer

Portland State University

Follow this and additional works at: https://pdxscholar.library.pdx.edu/open_access_etds

Part of the International and Intercultural Communication Commons, and the Sociology Commons Let us know how access to this document benefits you.

Recommended Citation

Mayer, James C., "Toward a test for ethnocentrism and ethnorelativism based upon reference group orientation" (1980). Dissertations and Theses. Paper 3059.

https://doi.org/10.15760/etd.3048

This Thesis is brought to you for free and open access. It has been accepted for inclusion in Dissertations and Theses by an authorized administrator of PDXScholar. Please contact us if we can make this document more accessible: pdxscholar@pdx.edu. 
AN ABSTRACT OF THE THESIS OF James C. Mayer for the Master of Arts in Speech Communication: Emphasis in Intercultural Communication presented November 21, 1980.

Title: Toward a Test for Ethnocentrism and Ethnorelativism Based Upon Reference Group Orientation

APPROVED BY MEMBERS OF THE THESIS COMMITTEE:


Theodore Grove

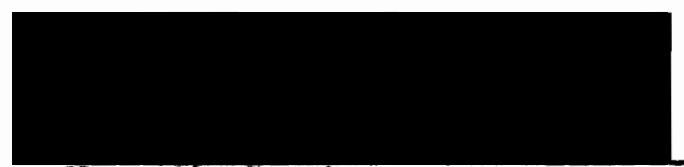

Naguib Greis

The object of this investigation is to determine whether two aspects of reference group orientation, 1) multiplicity and 2) structural variation, are possible indicators of ethnocentrism. Most of the thesis is devoted to a theoretical formulation in which reference group orientation and ethnocentrism are placed in a perceptual framework. Reference group orientation is defined as a person's use of a frame of 
reference that is formed through adoption of a reference group's perspective. Ethnocentrism is defined as a person's use of a frame of reference that keeps him from accepting the viability of other cultural frames of reference. The acceptance of the viability of other cultural frames of reference is defined as ethnorelativism. A flexible formation of cultural identity creates the conditions for a large number (relatively high multiplicity) and broad diversity (relatively high structural variation) of reference group orientations. It is hypothesized that those people who are aware of higher multiplicity and higher structural variation of reference group orientations will be more likely to accept the viability of other cultural frames of reference.

A pilot study is performed in which twenty-one students from an undergraduate Speech Communication class at Portland State University are given two tests. In the first test, called the "Who are you?" test, the students indicate the multiplicity and structural variation of their reference group orientations. In the second test, called the "Acceptance/rejection of other cultural frames of reference" test, the students indicate the degree of their ethnocentrism.

The degree of association between the students' responses on the two tests is measured by using the Pearson "r" coefficient. Results suggest that a moderately positive degree of association exists between both high multiplicity and high structural variation of reference group 
orientation and the acceptance of other cultural frames of reference. Recommendation is made for further investigation of multiplicity and structural variation of reference group orientation as aspects of ethnocentrism and ethnorelativism. 
TOWARD A TEST FOR ETHNOCENTRISM AND ETHNORELATIVISM BASED UPON REPERENCE GROUP ORIENTATION

\author{
by \\ JAMES C. MAYER
}

A thesis submitted in partial fulfillment of the requirements for the degree of

\author{
MASTER OF ARTS \\ in \\ SPEECH COMMUNICATION \\ EMPHASIS IN INTERCULTURAL COMMUNICATION
}

Portland State University

1980 
TO THE OFFICE OF GRADUATE STUDIES AND RESEARCH:

The members of the Committee approve the thesis of James C. Mayer presented November 21, 1980.
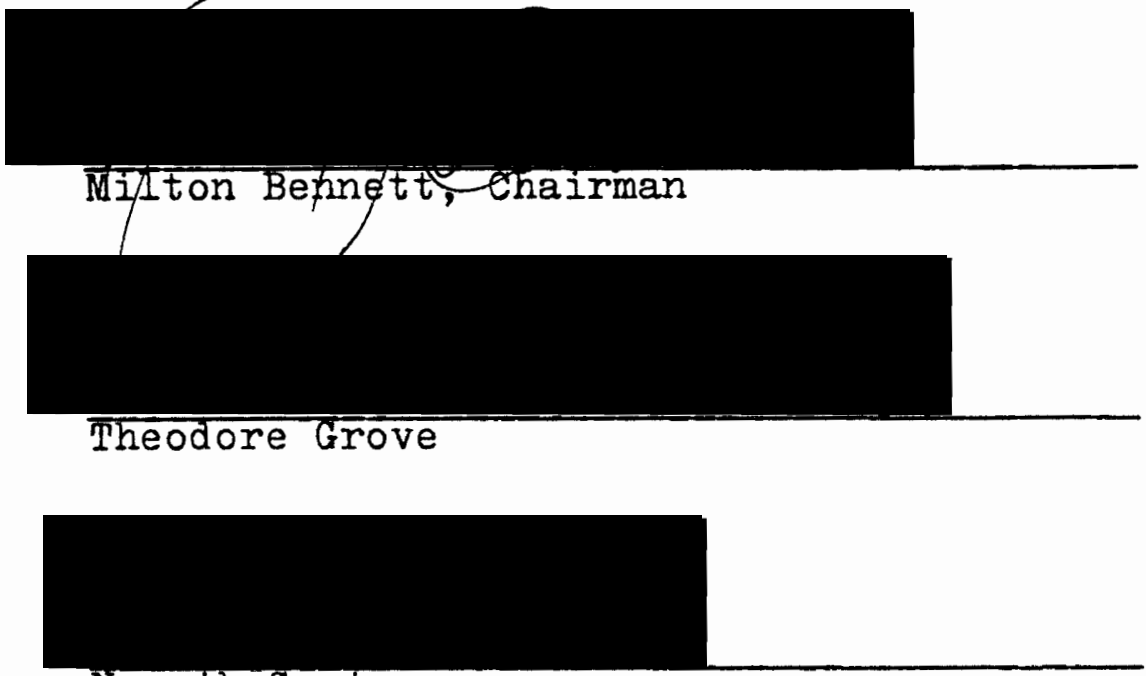

Naguib Greis

APPROVED:

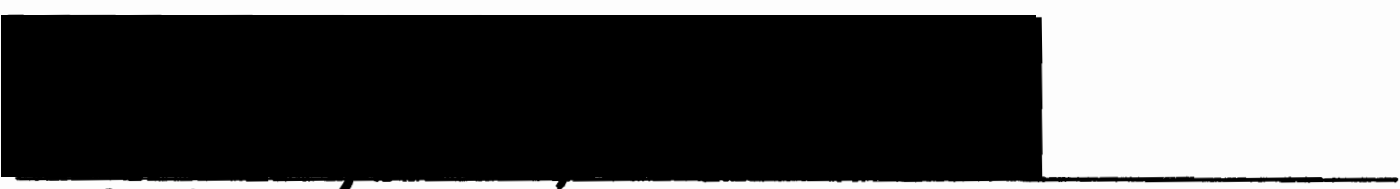

Frank Roberts, fead, Department of Speech Comminication

Stanley E. Raúch, Dean of Graduate Studies and Research 


\section{ACKNOWLEDGMENTS}

I would like to express grateful appreciation to $\mathrm{Dr}$. Milton Bennett, who suggested ethnocentrism as a topic in the first place. I greatly enjoyed the many hours that we spent discussing this project. Also, I wish to thank Dr. Theodore Grove for his cooperation, and especially for his helpful criticisms in the early stages of the thesis' development.

I want to acknowledge the students at Portland State University who took the tests for the pilot study, and their teacher, Mr. Ed Cavin, who so willingly cooperated in the administration of the tests.

To my father-in-law, Ed Wittwer, I extend my heartfelt thanks for serving on the panel of judges. And to Carol, whose love and support made it all worthwhile, I thank most of all for being a judge, proofreader, typist, spelling teacher, wife and bearer of Geneva, a body of work that far surpasses this one. 


\section{TABLE OF CONTENTS}

"Everything of importance has been said before by somebody who did not discover it."

A. N. Whitehead

PAGE

ACKNOWLEDGMENTS

LIST OF TABLES

CHAPTER

I INTRODUCTION $\cdot$. . . . . . . . . . .

The Assumption of Cultural Dif-

ference and the Assumption

of Cultural Similarity

Major Purposes of the Thesis . . . . 6

II SYMBOLIC INTERACTIONISM AND THE NEED

FOR THE REFERENCE GROUP CONCEPT . . . .

An Interactionist Perspective on

Society and the Individual ... .

The Reference Group Concept in the Context of Society and the Individual

Conclusion . . . . . . . . . . .

III COMPARATIVE AND NORMATIVE REFER-

ENCE GROUPS: A SYNTHESIS.

An Overview of the Basic Divi-

sion of the Reference

Group Concept . . . . . . . .

A Division of the Reference

Group Concept Based on the

Interactionist Tradition 
An Interactionist Theory of the Reference Group Concept

Summary • • • • • • • • • •

IV THE NATURE OF ETHNOCENTRISM . . • . • .

Traditional Aspects of

Ethnocentrism . . . . . . 26

Major Theoretical Treatments

of Ethnocentrism .. . . . . 28

Ethnocentrism as a Percep-

tual Process

Ethnorelativism

Summary

V A REVIEW OF TESTS USED TO

MEASURE ETHNOCENTRISM

Two Kinds of Ethnocentrism Tests That Are Based on Attitudes

Tests That Measure Attitudes

Toward Other Groups . . . . . .

The Concept of Mental Rigidity . . .

Tests That Measure a Rigidity

Factor of the Personality

Summary

VI ETHNOCENTRISM AND THE NEED FOR

THE REFERENCE GROUP CONCEPT

The Basis for Setting a

Perceptual Framework . . . . .

Ethnocentrism and Reference Group Theory . . . . . .

Conclusion.

VII THE RATIONALE FOR STATING THAT

ETHNOCENTRISM AND ETHNO-

RELATIVISM ARE BASED UPON

REFERENCE GROUP THEORY . . . . . . • 
The Role of the Formation of Cultural Identity . . . . . .

Enculturation: a Basis for

the Perceptual Process in

Ethnocentrism and

Ethnorelativism . . . . . . . •

The Enculturation Process as

Reference Group Orientation . . .

The Nature of the Formation of Cultural Identity . . . . . . .

Two Aspects of Reference Group

Orientation: (1) Multiplicity

and (2) Structural Variation . . .

Conclusion

VIII HYPOTHESES

IX PILOT STUDY • • • • • • • • • • • • • •

Purpose of the Pilot Study . . . .

The "Who Am I?" Test and the "Who Are You?" Test . . . . . . . .

The "Acceptance/Rejection of Other Cultural Frames of Reference" Test

Results and Discussion of the

Pilot Study . . . . . . . . .

Conclusion . . . . . . . . . . 83

X APPIICATIONS • • . • . . . . . . . •

Teaching English as a Second Language • • • • • • • • • •

Overseas Training: Awareness of

Alternative Reference Group

Orientations . . . . . . . . .

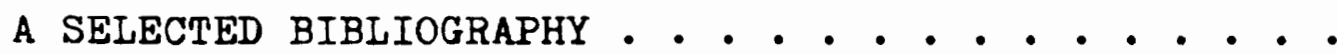


Appendix A: The "Who Are You?" Test . . . . . . . . . 98

Appendix B: The "Acceptance/Rejection of Other Cultural Frames of Reference" Test . . . . . . . 99

Appendix C: Directions for Panel of Judges . . . . . . . . . 101 Appendix D: Glossary . . . . . . . 103 


\section{LIST OF TABLES}

TABLE

PAGE

I Raw Scores . . . . . . . . . . .

81

II Degree of Association between the "Who Are

You?" Test and the "Acceptance/Rejec-

tion of other Cultural Frames of

Refərence" Test . . . . . . . .

83 


\title{
CHAPTER I
}

\author{
INTRODUCTION
}

THE ASSUNIPTION OF CULTURAL DIFFERENCE AND THE ASSUMPTION OF CULTURAL SIMILARITY

Central to any discussion of ethnocentrism is the importance of both the assumption of cultural difference and the assumption of cultural similarity. In this part of the introduction, I will present, first of all, two positions which have divergent means to a common end. These positions are (A) the recognition that the world is, after all, like one single culture, and (B) the non-evaluative recognition that there are vast cultural differences throughout the world. Proponents of both of these philosophical positions believe, paradoxically, that their viewpoints point the way to global harmony. Advocates include, for the first position, people who espouse a universal 'human nature', and for the second position, people who are involved in theoretical, educational and training aspects of intercultural communication. Next, I will offer two views currently extant in the United States: 1) the belief in a common U.S. culture, and 2) the belief in ethnic pluralism. The former view, like the recognition that the world is like one single culture, assumes cultural similarity among people. The latter 
view appears to assume cultural difference. However, this is actually a smokescreen for an ulterior assumption of cultural similarity, as I will explain later in this chapter. Finally, I will conclude that the assumption of cultural similarity among people, in the form of 1) a belief in a common U.S. culture, 2) a belief in ethnic pluralism, or 3) a belief in universal 'human nature', reflects an ethnocentric perspective.

The first position to be discussed is that held by those people who claim that the assumption of cultural similarity is correct because there is a universal 'human nature' that transcends cultural boundaries. These people believe that by trusting in 'human nature', which is basically good, any social problem can be overcome.

This position is based upon the fact that one of ethnocentrism's major impacts is that it can produce perceived cultural differences. That is, if someone feels superior or rejects people from groups other than his own, he may be perceiving cultural differences between them and himself. Persons who believe in the efficacy of a universal 'human nature' find prejudice and other forms of rejection of people offensive. Because prejudice can stem from perceived cultural differences, the universal 'human nature' believers view the assumption of cultural difference as harmful.

However, the assumption of cultural difference is not 
equivalent to the evaluation of cultural difference. Many believers in an ultimate 'human nature' do not recognize this distinction. In their mind, the evaluation of other people, based upon the differences between them, may be negative. Thus, they would say that we should stop emphasizing the similarities of people everywhere.

A quite different answer is to minimize as much as possible the evaluation, either negative or positive, while emphasizing the cultural differences between people. This position is exemplified by intercultural theorists who maintain that non-evaluative perception of cultural difference is the key to global understanding. By recognizing cultural differences in the worla, without initially or primarily evaluating them, one is "seeking to preserve whatever is most valid, significant and valuable in each culture as a way of enriching and helping to form the whole" (Adler 1976, p. 364$)$.

The ability to consistently recognize significant aspects of other cultures, without prematurely regarding those aspects favorably or unfavorably, is a difficult, but necessary objective. An essential ingredient to this ability is the non-evaluative assumption of cultural difference. The position of intercultural communication theorists is that when this ingredient has been successfully and completely blended into our perceptions of other cultures, then the ultimate objective of unifying the world's people will be 
more easily attained.

In the U.S., there has been a controversy existing for a few years between two views, one of which ostensibly assumes cultural differences and the other which assumes cultural similarity. First, the 'new ethnicists' are the spokesmen for the descendants of immigrants mainly from southern and eastern Europe, "whose forebears immigrated to the U.S. between 1865 and 1924" (Novak 1973, p. 40). The 'new ethnicity' sprang from a "growing sense of discomfort with the idea that one is supposed to be universalistic, 'melted', or like everyone else" (Perlmutter 1977, p. 718) However, in seeking to find a "fascinating continuum of difference" (Novak 1973, p. 43), their attempt is merely a means to the selfish end of asserting one's own ethnic group identity. Once that identity is established, the potential danger is that one may become so taken with his own group's identity that he uses it as a standard for judging people from other groups. If this happens, he begins to operate ethnocentrically. This ethnocentrism is, thus, a manifestation of the assumption of cultural similarity, since, in his mind, everyone should be using the same standard as him.

A view which discourages the recent emphasis on ethnic origin is that of the 'melting pot' theorists. Their position extols the assumption of cultural similarity as a desirable facet of American society. That is, they assert that a 
common nationality and culture have begun to develop in the U.S. based upon a heritage which the vast majority of Americans share. This heritage is that most people came enthusiastically and voluntarily to the U.S. to "give up old customs and enter into a common society" (Glazer 1980, p. 63). To highlight American society's ethnic pluralism, the antiethnicists feel, would be inconsistent with the reality of our common culture.

The belief that a common heritage must be maintained, like the assertion, "We're all human, after all", is borne of an ethnocentric perspective. If we assert the existence of a common heritage, then who decides upon the limits and conditions of belonging to this common heritage? Certainly, those who espouse the existence of a common heritage aren't going to feel that they are excluded from being a part of that common heritage.

In summary, four positions which exemplify the assumption of cultural similarity and the assumption of cultural difference have been examined. The two positions associated with the assumption of cultural similarity both promote ethnocentrism since the discovery of that point of similarity, in the first case, 'human nature', in the second case, a common heritage, requires a single-reality perspective to identify it. Likewise, the position of the 'new ethnicists', although it assumes cultural difference, fosters ethnocentrism since this assumption may become so evaluative that one pits his own ethnic group against all others and views 
them through his group's eyes. To eliminate ethnocentrism, then, is to move to a multiple-realities perspective, which means accepting that others follow different cultural guides and use different standards for their judgments. In this thesis, the assumption of cultural difference, when held in a non-evaluative manner, is a pre-requisite for overcoming ethnocentrism. Such an assumption produces a readiness, and perhaps a willingness, to understand and accept cultural differences. By managing cultural diversity in this manner, there will develop better and more permanent intercultural communication.

MAJOR PURPOSES OF THE THESIS

I have begun this thesis with an assertion of the value that the assumption of cultural difference can have for effective intercultural communication and global understanding. I have placed this discussion as an introductory subsection because the belief in the efficacy of assuming nonevaluative cultural differences is the underlying frame of reference throughout the thesis. The present subsection comprises the latter half of the introductory chapter because it prepares the reader for what is to come in subsequent chapters.

In chapter II, I will provide the theoretical background for the reference group concept by tracing its roots to the fertile ground of symbolic interactionism.

In chapter III, I will provide the major components 
of reference group theory, based upon the recognized division between normative and comparative reference groups. At the end of this chapter, I will offer an analysis of the reference group concept which is based upon the reality of human behavior, and thus, is amenable to practical application. Any application of the reference group concept must also utilize an interactive perspective. I have chosen to apply the reference group concept to an analysis of ethnocentrism, because ethnocentrism is, itself, a social phenomenon and must be seen in terms of an individual's interaction with society. A major purpose of the rest of this thesis is to examine ethnocentrism in terms of an individual's orientation to his reference groups.

In chapter IV, I will discuss the nature of ethnocentrism. From that discussion, it will be shown that the most important aspect of ethnocentrism, and the one upon which the use of the reference group concept in this context has been based, is that an ethnocentric person denies the viability of other frames of reference. One who does not deny the viability of other frames of reference is, thus, an ethnorelative person. A further purpose of the thesis is to increase understanding of ethnocentrism and ethnorelativism. The social process, as I've proposed, is interactive. By holding an ethnocentric position, a person limits the quantity and quality of these interpretations. Another significant purpose of the thesis is to examine the possibility that an ethnorelative position can be attained through ini- 
tially gaining an awareness of one's reference group orientations. The more that one is aware of her own reference group orientations, the more she can appreciate that others have established their own equally viable reference group orientations. Stimulating this appreciation may be one way to teach and train intercultural communication to people more effectively. Thus, a related purpose is to suggest that attainment of ethnorelativism promotes greater ability for intercultural communication, which, in turn, invigorates the number and kind of one's interpretations of the social process, which, in turn, promotes greater ability for intercultural communication, and so forth.

A final purpose of the thesis is to lay the groundwork for a new test of ethnocentrism and ethnorelativism, and one which will be more basic than existing tests. First, I will attempt to show that existing tests of ethnocentrism are designed to measure "How much" ethnocentrism without even heeding "What kind" is being considered. The motivation for developing a new test is to answer a more basic question than "How much" or "What kind", and that is: "Why is a person more or less ethnocentric than other persons?" Then, I will examine, very specifically, the basis for associating ethnocentrism with reference group orientation. From this discussion, some propositions will be generated. These propositions will be tested, and hopefully, we will have found a basis and direction for a way to accurately measure ethnocentrism and ethnorelativism. 
CHAPTER II

\section{SYMBOLIC INTERACTIONISM AND THE NEED FOR} THE REPERENCE GROUP CONCEPT

\section{AN INTERACTIONIST PERSPECTIVE ON SOCIETY AND THE INDIVIDUAL}

Emphasizing the cultural differences among the people of the world invites the desire for understanding those differences. Increasing this understanding, in turm, revitalizes the interactions between people. This renewal of our disposition to being social may be that unifying element that we like to refer to as 'human nature'

For all humans who are born into the company of other humans, a dynamic interactive cycle exists between an individual and society which is developed and experienced as much through society's effect upon an individual as through the individual's effect upon society. This proclivity for interacting with others has its roots in the experience one has as a child with his 'primary groups'. By 'primary groups', I mean those relatively permanent sets of others from whom the child learns that he and they are inseparable phases of a common whole (Cooley 1937, p. 26). This 'primary-group nature', as Cooley termed it, guarantees both that the individual creates any subsequent experiences and that the experience is social. 
This interaction between an individual and those first sets of others is managed by communication: a coo, a babble, a wail, which may call forth a glance, a stroke, some soothing words. Through communication, thought and mind are developed. This development triggers a mechanism which enables one to become an object to herself because those others are there to provide a vantage point from which she can see herself. The propensity for, as mead called it, "taking the attitude of others", begins in those early experiences with primary groups. This taking of others' attitudes becomes so well practiced that one eventually lumps all of these attitudes into one common impression. Mead called this impression the 'generalized other' (Mead 1934, p. 154).

The interactive cycle between society and an individual is premised upon the existence of a human social process. The social process creates the conditions for an individual to use the 'generalized other'. In this way, the impact of the social process is felt prior to actual face to face interaction between people. For example, suppose two people are in a potentially interactive situation, such as when one is meeting a friend at the train station. Before they meet, each is able to see himself as he perceives the other sees him. An equally ripe condition for an individual's use of the 'generalized other' would be a person who is isolated, such as a prisoner in solitary confinement. He calls upon a 'generalized other' each time he perceives himself. In these examples, we see an emphasis upon the formation of, 
what Mead called, the 'me', an 'organized set of attitudes of others which one himself assumes" (ibid. p. 175).

The use of the 'generalized other' would be stalled at this point were it not for one's ability to respond to the attitudes of others. That which responds Mead called the ' $I$ ', and it is significant that the ' $I$ ' is "responding to a social situation which is within the experience of the individual" (ibid. p. 177). That is, we continue to feel the impact of the social process prior to, or outside of, actual interactive situations. The prisoner and the two friends in the previous examples all feel this impact equally. Each is adept at reacting to the self which arises through taking the attitudes of others.

The relationship between the 'I' and the 'me' operates as a continual trade-off. We are constantly setting up responses, which we, then, immediately imagine. The action of setting it up, performed by the ' $I$ ', is never certain because one is never aware of it while it is occurring. As soon as the response occurs, one is already perceiving it, i.e. the 'me' has taken over, and is ready to make another response.

How one manages this relationship assures that there will be something "novel in experience" (ibid. p. 178). It is the source for each person's unique construction of reality. The individual's effect on, or contribution to, society comes from this source. From it, one is altermately moved to speak persuasively to some people, meekly to others; to 
avoid talking to someone by ignoring her, or to initiate a conversation with a stranger.

Actual face to face involvement with other people serves to invigorate the operation of the' $I$ ' and the 'me'. Again, communication between people manages the social process. When two people are offering their own unique construction of reality to the other, they may potentially alter each other's perception of her own 'generalized other'. For example, a woman begins to describe her recent childbirth experience to another woman who is obviously amazed at what a positive experience the first woman has had. Previously, the second woman has only heard about negative birthing experiences, and she now describes these to the first woman. The next time that each of these women discusses childbirth with other people, she will be aware of a slightly altered 'generalized other', to which she responds differently than before. The construction of reality concerning childbirth which each woman now offers may also be amended.

Physical involvement with others is on the same level of reality as psychical involvement. This was one of Mead's main corrections of Cooley's theory, which placed too much emphasis upon psychical involvement (Ürry 1973, p. 5). Actually, an individual's sense of the effect of society is similar whether she is living in indefinite isolation or is enjoying a gregarious life. A person can operate socially whether she is physically involved with those around her or 
psychically involved with people that she has never met before. The realization of this fact led to the development of the reference group concept.

THE REPERENCE GROUP CONCEPT IN THE CONTEXT OF SOCIETY AND THE INDIVIDUAL

Most explanations for the development of the reference group concept point to its usefulness in accounting for all those people with whom one is psychically involved, and not simply physically involved. The explanations point out that non-membership groups have as much influence on an individual as do his membership groups (Merton \& Rossi 1968, p. 35; Sherif 1968, p. 86; Kuhn 1972, p. 175; Urry 1973, p. 17).

Unfortunately, this explanation misses the main point, which is that the reference group concept is part of an interactionist tradition. That is, the focus of the reference group concept, for many reference group theorists, is only on one of the interacting halves: the impact or influence of the groups upon the individual (and not the influence of the individual upon her reference groups). The point has also been made that most empirical investigations involving reference group analysis have, instead of concentrating upon the process of selection of reference groups, viewed the effect of having selected those groups (Urry 1973, p. 30; Hartley 1968, p. 238). Through these kinds of applications and explanations, the reference group concept has been used to posit a determinate one-way relationship between the 
group and an individual's action. The utility of the reference group concept is that it should help us to focus on the interaction of society and the individual.

The intentions of the reference group theorists was to find an attractive label for a notion which had previously been merely alluded to. Various allusions to some reference object can be found in the writings of the symbolic interactionists and their predecessors. However, none of the allusions were very specific as to the nature of the reference object discussed. Thoreau's 'different drummer' is an early example (Hyman \& Singer 1968, p. 6). James spoke of "thoughts of remote groups and individuals who functioned as normative points of reference" (ibid. p. 7). Cooley discussed "groups outside on one's immediate environment" (ibid. p. 6). Mead alluded to a reference group each time the context was the 'generalized other'. For these writers, "the other is never attended to with the discerning and analytic interest which they (Cooley, Dewey, Mead, Faris) give to the actor" (Kuhn 1972, p. 178). That is, in the symbolic interactionists' writings, the balance seemed to be tipped in favor of the individual. Thus, the reference group concept served to consolidate all of these social theorists' (Cooley, etc.) intimations of a reference object into one identifiable name. 


\section{CONCLUSION}

Communication both instigates the social process, and assures that the responsibility for maintaining the social process is shared equally by an individual and society. The reference group concept has the potential of being a truly interactive label. An accurate description of a reference group that satisfies this potential must be bi-directional. It must take into account that, first, an individual has an endless arena of reference objects at her disposal with which to organize her experience. Secondly, those reference objects have an influence upon the individual due to the individual's awareness of them, and regardless of whether or not those objects are aware of the individual. These two aspects of the reference group concept are inseparable if the concept is to be contingent upon the interactive perspective, a perspective which instigated the reference group notion in the first place. 


\section{CHAPTER III}

COMPARATIVE AND NORMATIVE REFERENCE GROUPS: A SYNTHESIS

\section{AN OVERVIEW OF THE BASIC DIVISION OF THE REFERENCE GROUP CONCEPT}

At this point, it is necessary to review the most popular treatments of the reference group concept, especially since they usually omit an explanation of the reference group's inception in the interaction between society and the individual. These treatments of the reference group concept will be presented first, in order to contrast them with the analysis, in the next two subsections, which are based on an interactionist perspective.

As a result of the reference group concept's "meteoric prominence" (Turner 1956, p. 316), various attempts at conceptual clarification of the term have been made. Most of these attempts honor Kelley's distinction between 'comparative' and 'normative' reference groups (Kelley 1968, p. 78). Taken altogether, however, these treatments of the term do very little to clarify the nature of the reference group concept, and in fact, lend justification to Sherif's prediction that the reference group concept could "become a magic term to explain anything and everything concerning group relations" (Sherif 1968, p. 85). 
I will offer the comparative/normative distinction as a starting point since it does contribute to a basic understanding of the reference group concept. The distinction recognizes two kinds of relationships between a person and reference group. The normative reference group denotes "a group whose values, norms and perspective one uses in defining a social situation" (Clark 1972, p. 11). The comparative reference group denotes "a group which the person uses as a reference point in making evaluations of himself or others" (Kelley 1968, p. 79).

Sherif's experiments relating frame of reference and social norms helped prepare the way for the normative reference group concept. Resilts of these experiments showed that when subjects, as members of a group, were presented with an ambiguous situation, they formed a frame of reference which was peculiar to that group. Moreover, when these subjects afterwards faced the same situation individually, they still perceived it using the group's frame of reference. Their shared experience was a lasting one because they had formed, during that time, a group standard or social norm (Sherif 1936, ch. 6).

This establishment of a standard became a major attribute in the explanation of the normative reference group concept. The other major attribute was that the standard, or norm, had to be enforced. That, is, after establishing the social norms for an individual, it was implied by the explanation that the reference group observes and evaluates the 
individual. Therefore, the individual is motivated to "gain or maintain acceptance in the reference group" (Kelley 1968, p. 78). Or, in Newcomb's analysis, he may be motivated to reject it, in which case it would be, not a 'positive reference group', but a 'negative reference group' (Newcomb 1960, p. 109).

However, here is where lack of agreement over clarification of the reference group concept can be observed. The utility of the distinction between positive and negative reference groups has not been asserted by all reference group theorists. Sherif, for example, maintained that since one is, at certain times, positively disposed, and at other times, negatively disposed, to the norms of any group, the distinction is superfluous (Sherif 1968, p. 88). Shibutani made the point that one may aspire to no longer be accepted by a reference group, and still see the world through its eyes (Shibutani 1968, p. 105).

Other inconsistencies of the normative reference group explanations stem from attempts at over-clarification, or from misinterpreting others' classifications. In some classifications, the attribute of "observing and evaluating an individual" has been taken on by the 'audience group' (Turner 1956, p. 328; Cain 1968, p. 196). In another classification, the 'audience group' doesn't even take notice of the individual (Kemper 1968, p. 33). The attribute of "seeking acceptance to a group" has been isolated in a 'status group' (Clark 1972, p. 11). Interestingly, "the group whose ac- 
ceptance one seeks" has been depicted erroneously by Turner as Shibutani's 'normative group' (Turner 1956, p. 327). Turner, as well as Clark, also misrepresents Shibutani's notion of "reference group as perspective", simply classifying it as another 'normative group' (Tumer 1956, p. 327; Clark 1972, p. 11).

This inconsistency in conceptual clarification is unfortunate because it inhibits the empirical usefulness of normative reference groups. With so much conceptual baggage, the term has become so unwieldy as to leave a minimum of consideration for the individual. That is, on tests designed to indicate an individual's orientation to normative reference groups, there is no room for the individual's recognition of a larger range or number of reference group orientations than those which appear on the tests. The reference groups are already given in the form of statements of attitudes, beliefs or opinions to which a subject is expected to somehow respond.

With the comparative reference group, the balance shifts to the individual and the groups that he employs to locate himself in a social situation. Originally, the comparative reference group was considered as a point of reference for evaluating one's status (Hyman 1968, p. 147). In Hyman's experiment, subjects were asked which groups and individuals they compared themselves with when thinking about seven categories of status: 1) social, 2) intellectual, 3) cultural, 4) looks, 5) general, 6) economic and 
7) prestige. The categories used were based upon preliminary interviews with the subjects. Iikewise, the reference groups used were drawn from the list of groups and individuals the interviewees had offered (ibid. p. 149).

An important, though limiting, aspect of the comparative reference group concept is that any group or reference object with which an individual is familiar could be his reference group. On the one hand, this aspect is important since it begins to recognize the potential types and number of reference objects that one might use. On the other hand, this conception is limited because it reduces the reference group to a mere check point with which one evaluates his position in a situation.

In the conception of the normative reference group developed in the literature, the responsibility for the relationship between the person and the reference object is upon society. In the conception of the comparative reference group in the literature, this responsibility is upon the individual. According to these conceptions, the individual is manipulated by his normative reference groups in the sense that their perception of the individual is paramount; conversely, the individual manipulates his comparative reference groups in the sense that his perception of the reference groups is paramount. 
A DIVISION OF THE REFERENCE GROUP CONCEPT BASED ON THE INTERACTIONIST TRADITION

The normative reference group's enforcement of norms for an individual is only made possible through that individual's perception of the reference group. For example, an individual who is about to ascend the peak of Mt. Everest may have, as a normative reference group, the mountain climbers who have already made it to the top. These accomplished climbers can produce standards for the novice only insofar as the climber has perceived them as being aware of him. The effect is the same when the normative reference group is more immediate. For example, a family's norms for one of its members exists, for that member, in the way she perceives the family perceiving her.

Similarly, when an individual makes comparisons using his reference groups, their perception of him, as generated by the individual's perception, cannot be ignored by him. Their perception may be part of his estimation of his social status. That is, when he judges his position in terms of, for example, an occupational group, he is, however briefly, seeing himself as he perceives they see him.

Thus, it is impossible to talk about the reference group's evaluation of the individual without including the individual's perception of the reference group, and vice versa. The essential point is that there is an interactive process between the individual and her reference group. In Shibutani's reference group analysis, there is an 
attempt at incorporating this interactive process in his explanation. For him, a reference group contains both comparative and normative elements. He brings these elements together by emphasizing the perceptual aspect involved. This perceptual aspect is not stated in terms of perceiving a reference group "out there", in order to judge one's social position. Instead, it is stated in terms of a reference group providing an outlook or perspective, which an individual "uses as the frame of reference in the organization of his perceptual field" (Shibutani 1968, p. 107). This perspective is shared by an individual with others whose approach to the world is the same as that individual's. Shibutani stressed that the taking of the attitude of others is facilitated when one shares a perspective with those others, as would be the case, for example, with members of the same cultural group (ibid. p. 106).

\section{AN INTERACTIONIST THEORY OF THE} REFERENCE GROUP CONCEPT

In offering yet another clarification of the reference group concept, I hope to simplify rather than undermine it. Three related points are relevant. First, in order to have a reality-based analysis, reference group orientation must be viewed as a truly interactive process between an individual and his reference groups. Secondly, this explanation must involve a synthesis rather than a separation of the normative and comparative reference groups. Thirdly, we can 
simplify reference group orientation, and still maintain the first two points, by viewing reference group orientation as a perceptual process.

The synthesis between the normative and comparative aspects is analogous to the dynamic relationship between Mead's 'I' and 'me'. Just as one's 'I' sets up a response, an individual, by referring to a reference group, sets up, or expects, a potential response from it. When this comparative aspect has barely begun, the normative aspect, similar to the 'me', has taken over. That is, as soon as the set-up occurs, one imagines how it would be to see himself through that reference group's eyes, i.e. he develops their outlook, and this immediately affects how he perceives the world. Then a different situation may force him to turn to another reference group so as to reform his perspective. Or, he may maintain that reference group regardless of the situation. In either case, the individual and his reference group, like the ' $I$ ' and the 'me', are continually interactive.

The most important resultant of the simultaneous actions of setting up and imagining a response from a reference group is the formation of a frame of reference. This frame of reference, which has been induced through adoption of the perspective, is a perceptual filter that is replaceable, depending upon the reference group to which one is orienting herself. One value of considering a reference group as a perceptual filter is that it allows us to account for fic- 
tional or imaginary reference groups as easily as real ones, or for reference groups which exist in the present as well as those which existed in the past or will exist in the future.

Fundamental to this view of reference group orientation is the notion that each individual constructs his own reality. That is, the reference groups that each of us uses depend upon our constructions of reality. In these constructions, we use 'typificatory schemes' (Berger \& Luckmann 1967, p. 33), which may be as concrete as 'my friend Harry', or as anonymous as 'my immigrant great grandparents' (ibid. p. 33). These 'typificatory schemes' enter into our face to face situations, in that we refer to them while communicating with others. They are also available to us when we are not in face to face situations, as for example, when someone is thinking about what she will say to another person, or when one is preparing a speech. The ability to use 'typificatory schemes' is the basis for orienting ourselves to reference groups.

\section{SUMAMARY}

In the past few decades, the reference group concept became a popular term for describing the various groups that have some effect upon each individual. However, viewing reference group orientation in terms of the groups' impact upon individuals ignores the interactional character of social relations, which states: reference individuals and 
reference groups influence an individual as much as an individual influences his reference individuals and reference groups.

A widely accepted division of the reference group concept is the distinction between normative and comparative groups. In the comparative reference group, a person views himself with respect to that group. In the normative reference group, a group evaluates a person according to the standards, or norms, of that group. The normative aspect of reference groups has been too finely distinguished in the literature, so that there exists some disagreement over the meaning of this aspect. Either aspect, comparative or normative, as it is usually discussed in the literature, describes only half of the social process.

In my analysis, the reference group concept is more inclusive yet more simplified. By combining the normative and comparative aspects, I have tried to portray most accurately the interactional nature of the social process. By considering these aspects as perceptual processes, I have suggested a simplification of our understanding of how an individual operates with respect to those people around her. 


\section{CHAPTER IV}

\section{THE NATURE OF ETHNOCENTRISM}

Now that a comprehensive and accurate analysis of the reference group concept has been made, I will turn to a discussion of ethnocentrism/ethnorelativism. Ethnocentrism is a multi-faceted term. In this chapter, I will consider some of the aspects most popularly associated with it. Although generally viewed as an attitude or ideology, and usually imbued with negative feelings, ethnocentrism will alternatively be approached here as a perceptual process, from which, for example, negative attitudes or an authoritarian ideology may result.

\section{TRADITIONAL ASPECTS OF ETHNOCENTRISM}

Ethnocentrism has an innate basis, according to many sources (Murdock 1937, p. 613). Descriptions of this innateness have been stated in terms of a "manifestation of a herd instinct", or a "form of group egotism (common) among those animals which live in societies" (ibid. p. 613).

More commonly, however, ethnocentrism has come to be viewed in human society as a very significant cultural factor. The responsibility for developing this view lies with Sumner, who gave ethnocentrism its name (Sumner 1906, 
p. 13). Because of Sumner, most notions of ethnocentrism

are based upon the distinction between ingroups and outgroups, terms which were also first coined by Sumner (ibid. p. 12). Naturally the widely acknowledged definition of ethnocentrism comes from Sumner also:

a view of things in which one's own group is the center of everything, and all others are scaled and rated with reference to it. Each group nourishes its ow pride and vanity, boasts itself superior, exalts its own divinities, and looks with contempt on outsiders. Each group thinks its own folkways the only right ones, and if it observes that other groups have other folkways, these excite its scorn (ibid. p. 13).

The impact of his analysis has been felt for most of this century. From his definition, four main aspects of ethnocentrism can be isolated: 1) that one's own group or customs are used as a standard, 2) that the rating of other groups is hierarchical, i.e. in terms of greater or lesser similarity, 3) that one evaluates differences, i.e. he points out things that are peculiar and that differentiate him from others, and judges them, and 4) that one expresses ingroup acceptance, positiveness, loyalty, amity, superiority and outgroup rejection, negativeness, hostility, inferiority. This aspect will henceforth be simplified to 'ingroup acceptance/outgroup rejection'.

These aspects have been mainly relied upon by subsequent writers who have contributed to the ethnocentrism literature, especially those writers who have attempted to measure ethnocentrism. I will, therefore, consider them as the traditional aspects of ethnocentrism. 
MAJOR THEORETICAL TREATMENTS OF ETHNOCENTRISM

A very significant investigation of ethnocentrism, in which these traditional aspects were maintained, emerged with The Authoritarian Personality (Adorno et al 1950). According to the authors, ethnocentrism is an ideology based primarily upon a need to make an ingroup acceptance/outgroup rejection distinction. They pointed out two interesting characteristics of this distinction. First, the outgroup rejection is very general. That is, an ethnocentric person perceives that all groups, other than those in which he has a sense of participation, are somehow threatening to him. Secondly, an ethnocentric person's outgroup fluctuates easily between various social contexts. Thus, he could quickly move from; for example, an anti-Arab to an anti-catholic to an anti-communist position.

The other three aspects have also been utilized in Adorno et al's framework. First, recognition of evaluative differences is closely involved in the flexible placement of outgroups. Secondly, the standard for making the ingroup acceptance/outgroup rejection distinction still comes from one's ingroup. Thirdly, the rating of all outgroups is, in their words, "arranged like a series of concentric circles around a bull's eye" (ibid. p. 148).

One important aspect of ethnocentrism, which was not already pointed out by Sumner, developed from Adorno et al's investigation. This aspect is that ethnocentrism is part of 
a broad ideological structure of the personality. Their investigation indicated that the ideological structure was characterized by their negatively evaluated quality of a politically right, conservative, even fescistic authoritarianism.

Rokeach further investigated this aspect and discovered that this structure in the personality was not quite what Adomo and the other Califormia scholars had thought. Ethnocentrism, he claimed, could be part of either a right or a left authoritarian ideology, since the crucial factor is a structural rigidity in the personality that is less flexible than any ideological content one could hold. This rigidity factor shows up in people who can't tolerate delay of satisfaction of needs. Since this delay is a threat to ctheir egos, these people learn to reduce their frustration by responding in rigid ways (Rokeach 1948, p. 259).

As the general theory of rigidity developed, the rigidity factor came to subsume other concepts such as 'dogmatism', 'opinionation' (Rokeach 1960), 'defensive behavior' (Brown 1953), 'intolerance of ambiguity' (Frenkel-Brunswik 1949). Thus, although linking ethnocentrism to a structure of the personality had important theoretical ramifications, it tended to generalize rather than specify the nature of ethnocentrism. Also, these concepts maintain the negative connotation given to ethnocentrism by Sumner and Adorno et al. As I will discuss in the next chapter, such concepts can be easily rendered as attitudes for use on tests. 
Another aspect which stemmed from the California investigation is that ethnocentrism is actually "prejudice, broadly conceived" (Adorno et al 1950, p. 102). That is, ethnocentrism is prejudice directed toward a wide range of groups. Subsequent investigations of ethnocentrism have, as we will see in the next chapter, profited from this aspect. Yet, other people have pointed out that if the California authors are treating prejudice, then their ethnocentrism scales should be described as measures of ethnic prejudice (Harding et al 1969, p. 13).

Williams makes an interesting separation between ethnocentrism and prejudice. He claims that an ethnocentric person indulges in feelings of social distance and stereotyping behavior before his behavior moves on to what could be called prejudice. Even then, he calls it a 'disengaged prejudice', held as a peripheral, and not a focal, concern (Williams 1964 , p. 32). Ethnocentrism does not always lead to prejudice, according to Williams, because ethnocentrism is not always characterized by negative feelings toward other groups. That is, positive feelings toward one's own group may include merely neutral feelings, such as ignorance of, or lack of interest in, other groups (ibid. p. 23). Thus, prejudice is an effect of some, but not all, kinds of ethnocentrism.

This aspect of ethnocentrism, that non-negative feelings toward another group may be involved, is extremely 
significant because it upsets the accuracy of one of the traditional aspects of ethnocentrism: the ingroup acceptance/outgroup rejection distinction. That is, the views of ethnocentrism which include this distinction are already looking beyond the nature of ethnocentrism and concentrating on its potential effects, in this case, negative ones.

In other words, the essential nature of ethnocentrism has nothing to do with negative feelings toward others, because these feelings are the results of some, but not all, ethnocentric positions. Certain ethnocentric positions may result in neutral, or even positive, feelings toward other groups. For example, Swartz has observed that, with respect mainly to what they have heard about American technology and lifestyles, the Trukese on Romonum Island in Micronesia compare themselves unfavorably with Americans. They have developed ingroup negative/outgroup positive feelings, which Swartz calls 'negative ethnocentrism' (Swartz 1961). Yet, it is important to remember that this positive feeling toward Americans is as much an effect of ethnocentrism as is the negative feeling that they feel toward, for example, people on neighboring islands. In either case, these feelings (positive or negative) result from a single perspective, which pays as little heed to the perspective of the Americans as it does to the perspective of the neighboring islanders. 


\section{ETHNOCENTRISM AS A PERCEPTUAI PROCESS}

Fortunately, there is a conception of ethnocentrism that stops short of including what may result from ethnocentrism, and thus, does not confuse the effects of a phenomenon with the phenomenon itself. Conceiving ethnocentrism as a. perceptual process accomplishes this goal. To restate the previous example, the Trukese have formed their own frame of reference which denies the existence of both the Americans' and the other islanders' frames of reference. This aspect of ethnocentrism has been pointed out by Porter, who calls it a view that "produces a frame of reference that denies the existence of any other frame of reference" (Porter 1976, p. 10). I believe that it illuminates the nature of ethnocentrism more than any other aspect.

The core notion of ethnocentrism is that an ethnocentric person presents to himself a perceptual boundary. His allegiance is drawn to what is within this boundary, at the same time excluding, or remaining unaware of, what is within others' boundaries. In a later chapter, I will place this notion in a cultural context.

The aspect of ethnocentrism as restricted perspective can most effectively be stated in these terms: an ethnocentric person uses a frame of reference which denies the viability of other (than his own) frames of reference. By "denies" I do not intend an active sense of rejection, scorn, disdain or even refusal. Rather, I mean a more pas- 
sive "unwittingly deprives oneself the knowledge of", or "lacks awareness of". The meaning of "viability" has two components. It includes, first of all, "possibility for existence". Once this possibility has been established, a sense of "workability" also arises. By "frame of reference" I mean a perceptual filter produced by either direct or vicarious orientation in a reference group.

Stagner, likewise, explains ethnocentrism as a perceptual process (Stagner 1977). His explanation begins with Piaget's notion of 'egocentrism'. A child begins by being egocentric, i.e. a child is the center of his own universe. He cannot adopt the point of view of another person and see the world as it appears to that person. Egocentrism is characterized by "centration, i.e. focussing attention on a single feature of a situation to the exclusion of other important aspects" (ibid. p. 10).

Eventually, a child becomes capable of "attending to varied aspects of events and of adopting a perceptual stance which allows him to see facts as they appear when viewed by someone other than himself" (ibid. p. 10). Piaget called this 'decentration'. It occurs in the social sphere as a result of 'confrontations' with the child's mother, father, and other significant others in her environment. The child comes to be 'shocked' when she learns that there are discrepancies between the aspects of situations as she sees them and the aspects of the same situations as others see them. Soon, she is reconciled to the fact that others in 
her environment take account of reality differently than she does.

Stagner offers the view that egocentric perceiving becomes ethnocentrism. He maintains that a child symbolically acquires the 'facts' of her ethnic group which then determine how she will perceive other ethnic groups. Members of these other ethnic groups are not usually a part of her immediate environment as her mother and father are. Thus, she doesn't have an opportunity for 'confrontations' with people from other groups, and decentration cannot occur as readily. Her resultant failure to adopt a perceptual stance that would allow her to see the world as it appears to members of other groups is "ethnocentric perceiving" (ibid. p. 11).

\section{ETHNORELATIVISM}

In contrast to his notion of ethnocentrism, Stagner uses the term 'altrocentrism' to describe "that kind of perceiving in which a person may demonstrate understanding of the views of another person or group, hence, capable of seeing reality as others see it" (ibid. p. 12). In this thesis, I am using the term ethnorelativism to mean the converse of ethnocentrism. An ethnorelative person accepts, i.e. gains awareness of, the viability of other frames of reference. That is, she is ready to accept the potentiality of numerous frames of reference, the existence of which she hasn't yet been asked to accept. Moreover, she is able to vouch for the workability of each frame of reference. 
By using a perceptual framework, ethnorelativism can be stated in terms that are just as specific as those used for ethnocentrism. It is especially useful that ethnorelativism can be translated into stated objectives. This enhances the potential for 1) teaching someone to become more ethnorelative, and for 2) designing a test for ethnocentrism and ethnorelativism.

In contrast to the above suggestion, some discussions of ethnocentrism give only a general impression of what one may become if he desires to be less ethnocentric. Adorno et al, for example, used the terms 'anti-ethnocentrist' and 'non-ethnocentrist' for someone who does not have a need to make an ingroup acceptance/outgroup rejection distinction. In short, she "identifies with humanity as a whole" (Adorno et al 1950, p. 148). Sampson and Smith called such an identification 'worldmindedness' (Sampson \& Smith 1957).

The term 'internationalism' has also been used in this context (Levinson 1957). However, it is difficult to clearly spell out the means for achieving what these terms are describing. For instance, one could only vaguely explain the manner by which someone might become 'worldminded'. And yet, a consideration of the way to become less ethnocentric is essential for understanding the nature of ethnocentrism.

\section{SUMMARY}

The objective of this chapter has been to set forth a 
conception of ethnocentrism that 1) does not confuse ethnocentrism with other related, but not equivalent terms, or 2) does not treat the effects of ethnocentrism instead of the basic notion of ethnocentrism itself. Sumner, and most subsequent investigators of ethnocentrism, conceptualize ethnocentrism too broadly. Consequently, in their discussions, the essential nature of ethnocentrism is unclear. To consider ethnocentrism as a perceptual process clarifies it, and provides a more precise means for explaining the opposite of ethnocentrism, here termed ethnorelativism. 
CHAPTER $V$

A REVIEW OF TESTS USED TO MEASURE ETHNOCENTRISM

Certain theoretical treatments of ethnocentrism have undergone empirical investigation, in the form of tests or scales used to measure ethnocentrism. In this chapter, I will review several of these tests. It will become obvious that the influence of the traditional aspects of ethnocentrism on scholars who have attempted to measure ethnocentrism has been very strong. The point will be made that an understanding of the nature of ethnocentrism is not a major objective in designing or using these tests. The tests, like the theoretical formulations which preceded them and which helped to determine their make-up, are concerned with identifying the effects of ethnocentrism rather than identifying any basic quality of ethnocentrism. Moreover, these tests have been perceived by students of ethnocentrism as suitable for the purpose of identifying the effects of ethnocentrism because, first, traditional aspects of ethnocentrism have favored the view that ethnocentrism is made up of negative attitudes, and thus, these aspects can be more easily rendered through measurement of attitudes; and secondly, the development of a generalized conception of ethnocentrism has encouraged some scholars to equate it with similar, though not exactly comparable, concepts, such as 'in- 
tolerance', 'dogmatism', 'prejudice'. Thus, in these scholars' minds, ethnocentrism would be amenable to measurement on tests which are designed to measure these latter concepts.

\section{TWO KINDS OF ETHNOCENTRISM TESTS}

THAT ARE BASED ON ATTITUDES

Most tests that are used to measure ethnocentrism are Likert scale attitude statement questionnaires. In this format, ethnocentrism is measured according to the kind of attitudes expressed in the statements, which the subjects must choose to differentially agree or disagree with. Two categories of negative attitudes have been considered by test-users to be comparable to ethnocentrism: first, attitudes which are directed toward specific groups, such as 'prejudice', 'nationalism', 'social distance', 'lack of sympathetic identification with the underdog', 'intolerance', 'anti-worldmindedness'; secondly, attitudes which express a rigidity factor of the personality, such as 'mental rigidity', 'dogmatism', 'opinionation', 'fascism'. These two categories are not mutually exclusive. I have separated them simply because they represent two major ways of considering ethnocentrism. In fact, a rigidity factor in the personality might very well be a socio-psychological determinant of, for example, nationalistic attitudes.

Ethnocentrism is not best understood as being attitudinal in nature. Certain attitudes may be results of an ethnocentric, or an ethnorelative, perspective. Agreement with 
negative attitudes may show that someone is nationalistic, dogmatic or prejudiced, but not necessarily that he is ethnocentric.

Also, there is no necessary correlation between the extent of a person's ethnocentrism and his score on one of these tests. In only one case is there a correlation: a person whose ethnocentrism results in negative attitudes toward other groups will have a high ethnocentrism score on those tests which are based upon the view that ethnocentrism always leads to negative attitudes toward other groups. However, as was illustrated in the last chapter, an ethnocentric perspective may co-exist with positive attitudes toward other groups. Thus, a person who is actually quite ethnocentric, yet is positively disposed toward Black people, could disagree with the negative statements concerning Blacks on the Califormia Ethnocentrism Scale (Adorno et al 1950 , p. 110-11), thus receiving an inaccurately low score. Furthermore, an ethnorelative person might express agreement with negative attitudes concerning groups' behaviors on one of these tests, and thus receive a high ethnocentrism score. For example, a person may disdain the bribing of officials as it affects his own life, yet feel that it is acceptable behavior somewhere else. If the feeling of disdain determines his response to an attitude concerning bribery of officials, he will be considered ethnocentric. The test has not been able to accomodate the difference between a subject's indication of negative feelings for him- 
self with respect to that behavior, and his acceptance of the viability of that behavior for another group.

Therefore, the first priority in designing a test of ethnocentrism is to consider ethnocentrism before it becomes 1) an attitude toward other groups or their behavior, or 2) an attitude which expresses a rigidity factor of the personality.

TESTS THAT MEASURE ATTITUDES TOWARD OTHER GROUPS

I will review, first, those tests which are concerned with attitudes toward other groups or their behavior:

The Social Distance Scale (Bogardus 1933) purports to measure personal-group distance, in this case, the distance that someone perceives to exist between himself and members of other ethnic groups. Because this conception of social distance involves all of the aspects traditionally attributed to ethnocentrism, especially the aspect of scaling and rating other groups in a hierarchical fashion, the Social Distance Scale has often been used to measure ethnocentrism. A large score indicates the least degree of intimacy that an individual claims he would allow between himself and members of outgroups. Actually, this scale is designed to measure the feelings which certain ethnocentric persons might indulge in before they are disposed to behave in a prejudiced way. The popularity of this scale as an ethnocentrism test is undoubtedly due to its high reliability and content validity. 
The four versions of the California E scales, which all use the Iikert-style attitude statement format, are "intended to measure an individual's readiness to accept or oppose ethnocentric ideology as a whole" (Adorno et al 1950, p. 109). Their notion of "ethnocentric ideology as a whole" is based upon traditional aspects of ethnocentrism, especially ingroup acceptance/outgroup rejection distinction. For individuals responding to the E tests, the ingroup is comprised of 1) Anglo-Saxon, 2) politically conservative, 3) white, 4) male 5) Americans. Outgroups include Blacks, Jews, foreigners, Okies, zootsuiters, the insane, radicals, incapable people, even women. Thus, subjects are actually expressing their readiness to accept or oppose prejudice toward these outgroups.

The tests which came out of the California investigations have been highly respected because of high content validity. That is, the authors were very meticulous in "constructing empirical measures with characteristics appropriate to their conceptual definition" (Harding et al 1969, p. 13). Part of this conceptual definition, unfortunately, used the term 'ethnocentrism', and the use of this term has influenced subsequent investigators of ethnocentrism a great deal. For example, the empirical validity of many tests in the past thirty years that purport to measure ethnocentrism is based upon these tests' correlation with the $\mathrm{E}$ test. The empirical validity of the E test itself, based upon correlation with its own subscales, was quite high. 
The Internationalism-Nationalism Scale (Levinson 1957) has been used to measure ethnocentric thinking in the realm of international relations. Nationalism is considered here as "a facet of a broader ethnocentric orientation" (ibid. p. 38). Levinson bases nationalism on the traditional aspects of ethnocentrism, especially ingroup acceptance/ outgroup rejection distinction. The major characteristic of internationalism is a desire for limiting national sovereignty by means of reducing the barriers which now exist between nations; ideally, all nations would eventually enjoy "full exchange of ideas, commodities and cultural ways" (ibid. p. 39). Part of the evidence for the validity of this Likert-type scale was its .77 correlation with the $E$ test.

The Worldmindedness Scale (Sampson \& Smith 1957), another Iikert-type scale, distinguished conceptually between pro-worldmindedness/anti-worldmindedness and internationalism/nationalism. That is, the authors wanted to show that it is possible to be, for example, worldminded without necessarily having interest or knowledge in international affairs. Eight dimensions of worldmindedness were equally divided among the items on the scale. These dimensions were 1) religion, 2) immigration, 3) government,
4) patriotism, 5) race,
6) education, 7) economics and
8) war. The E scale is again used to support the empirical validity of this scale. Moreover, the authors argue for the Worldmindedness scale's intermal validity, maintaining that 
a "consistent value orientation appears to be operative throughout all the attitude areas in the scale" (ibid. p. 99). Yet, it is difficult to pin down the "identification with mankind" as a useful construct for a test. Whereas the Internationalism-Nationalism Scale was used to measure one facet of ethnocentrism, in turn, ethnocentrism is one facet of what the Worldmindedness Scale is attempting to measure. Por example, by agreeing with many of the proworldmindedness items on the test, one is overcoming a restricted perspective. That is, these items assume the desirability of accepting an unlimited number of countries, governments, races, etc.

One of the more common criticisms of the California $E$ test is that all of the items are negatively phrased, thus inclining subjects to acquiesce in their responses. To offset this shortcoming, the Intolerant-Tolerant Scale (Prentice 1956) was developed, with half of its items stating tolerant or supportive positions and the other half stating intolerant positions. The response mode was again a likerttype continuum, and only statements concerning Jews and Blacks are used on this scale. The traditional aspect of an ingroup acceptance/outgroup rejection distinction is missing on the half of the test with the items stating tolerant positions. The use of an ingroup's standard is not missing, however. Thus, a low score on this test, reflecting tolerant attitudes, would not necessarily indicate a low amount of ethnocentrism. After all, there is no assur- 
ance that, in the pro-Jewish or pro-Black person's statements, the standard used in making the statements is necessarily a Jewish or Black person's standard. The correlations with the $\mathrm{E}$ test, as if agreeing with this observation, are as follows: .86 with the negative half of the Intolerant-Tolerant Scale, and only .64 with the positive half.

A more recent test, which uses the Likert technique and attempts to validate itself through correlation with the E scale, is the Black Ethnocentrism Scale (Chang \& Ritter 1976). This test was developed because of the notion that Blacks have become increasingly ethnocentric, based upon stronger pro-Black and anti-White sentiments, i.e. ingroup acceptance/outgroup rejection, in recent years. Although a few items on the scale are directed against groups which could include non-Whites, most outgroup rejection statements on the test express anti-White sentiments. Thus, the test actually considers an extremely narrow conception of ethnocentrism, even based upon traditional notions of the outgroup.

Another recently developed test is the Ethnic Group Identification and Ethnocentrism Scale (Tzuriel \& Klein 1977). This test is concerned less with attitudes toward other groups than with attitudes toward one's own ethnic group. The authors minimize the ingroup acceptance/outgroup rejection aspect of ethnocentrism in favor of what they feel to be the major feature of ethnocentrism: "the degree 
of centrality on one's ethnic group in one's life" (ibid. p. 1100). This test uses the Likert technique and is divided into an Ethnocentrism subscale and an Ethnic Group subscale. No attempts were made to validate the Ethnocentrism subscale with other ethnocentrism tests, although one interesting correlation they did find was that low ethnocentrism scorers had more strongly formed ego identities (ibid. p. 1105).

One final test involving attitudes toward other groups is the "sympathetic identification with the underdog" questionnaire" (Schuman \& Harding 1963). This test consists of eleven simple stories. In each story, a minority group member is a victim of prejudice, and, for each situation, four possible ways are offered in which that person might react. In choosing the response that indicates "sympathetic identification with the underdog", the respondent is required to recognize the perspective of the minority group member. Interestingly, this recognition of another's perspective is not far from the conception offered in this thesis for ethnorelativism.

\section{THE CONCEPT OF MENTAL RIGIDITY}

Before reviewing those ethnocentrism tests that are concerned with attitudes expressing a rigidity factor of the personality, I will discuss the notion of rigidity and its relation to ethnocentrism. In the last chapter, I remarked that considering rigidity of the personality as a character- 
istic of ethnocentrism tends to generalize rather than to specify the nature of ethnocentrism. As a result of such a generalization, our understanding of ethnocentrism becomes obscured rather than illuminated.

A further reason that the understanding of ethnocentrism might suffer is because the rigidity concept itself is such a hard one to pin down. For example, Brown claimed that there is "no support for the popular assumption that rigidity is a term we all use and understand in much the same way" (Brown 1953, p. 469). He based this claim on the failure of the many investigations of rigidity to identify a "single general rigidity factor" (ibid. p. 469). More recently, Muhar examined whether or not six measures of rigidity (Keel's Scale of Authoritarianism, Coulter's Scale of Rigidity, Scale of Intolerance of Rigidity, and Dog-Cat Test of Rigidity, Rokeach's Map Test of Rigidity and Muhar's Test of Rigidity) were intercorrelated amongst themselves. His results indicated a lack of significant intercorrelation amongst the various measures (Muhar 1974). These numerous attempts at measuring and investigating rigidity are undoubtedly tapping different kinds of rigidity. Thus, one problem inherent in equating a rigidity factor of the personality with ethnocentrism is discovering the kind of rigidity that should be considered.

The original assertion that ethnocentrism and a rigidity factor of the personality are somehow related came from the work of Adorno et al (1950), who maintained that 
the kind of rigidity possessed by an ethnocentric person is a right authoritarianism. That is, ethnocentrism is part of a rigidly conservative authoritarianism which, in its extreme form, is akin to fascism.

Rokeach also felt that rigidity was a factor in ethnocentrism. His original thesis was that there is a generalized mental rigidity in an ethnocentric person's personality which would manifest itself in that person's solution of non-social, as well as social, problems. To substantiate this claim, he performed an experiment involving the solution of arithmetic problems. He found that a significantly larger percentage of high scorers than low scorers on the California $E$ test exhibited mental rigidity while attempting to solve the arithmetic problems. After the control problems have been solved by the experimenter, in which only one relatively complicated method of solution is possible, subjects are asked to solve several problems that could be solved by either the complicated or a much simpler method. Mental rigidity is exhibited, Rokeach claimed, by subjects who solved the problems by the complicated method. In a related experiment, Rokeach changed the type of problem from an arithmetic to a spatial one. Instead of capacities of water jars, subjects were presented with maps on which they were to find the shortest route between two points. Again, he found that more high than low scorers on the $E$ test identified complicated routes on the map problems. From the results of these two experiments, he concluded that 
the rigidity inherent in the solution of social problems is actually part of a pervasive mental rigidity that can be seen, as well, in the solution of non-social problems. Brown later attempted to find a significant relationship between problem-solving rigidity and ethnocentrism by replicating Rokeach's experiments (Brown 1953). Interestingly, he found no positive correlation except in situations where subjects were made to feel anxious over their achievement of solutions to the problems. Thus, he concluded that an ego-involving situation must be present before high ethnocentrism scorers would respond rigidly. The kind of rigidity associated with ethnocentrism, Brown maintained, is actually defensive behavior.

Another kind of rigidity, intolerance of ambiguity, has been identified as a factor in ethnocentrism (Block \& Block 1951). In their experiment, intolerance of ambiguity, or the tendency "to adopt an anchoring point quickly in an unstructured situation" (Taft 1956, p. 154), was measured by subjects' judgments of autokinetic movement of a light while the subject was sitting in a pitch dark room. Subjects who earliest wrote down the same distance repeatedly for the false motion of light, i.e. those who first established a norm in their responses, were identified as being intolerant of ambiguity. These responses were found to be statistically correlated with high scores on the E test. Other studies have also found a significant correlation between intolerance of ambiguity, based upon judgment of autokinetic 
movement, and ethnocentrism, where ethnocentrism is measured by, in one case, a social distance scale (Taft 1956), and in another case, the California $F$ test (Zacker 1973).

Thus, so far we have seen four possible descriptions of the rigidity concept: 1) right authoritarianism, 2) defensive behavior, 3) generalized mental rigidity and 4) intolerance of ambiguity. No ethnocentrism scale has been devised based solely upon intolerance of ambiguity as an equivalent concept for ethnocentrism. As we will see shortly, although Rokeach broadened his theoretical framework when he designed his scales, mental rigidity is essentially what the Dogmatism and Opinionation scales are measuring. As part of this new framework, he includes defensive behavior as a motivation for dogmatic thinking. And, right authoritarianism has been equated with ethnocentrism on the California $F$ test, which is discussed in the next subsection.

\section{TESTS THAT MEASURE A RIGIDITY FACTOR}

OF THE PERSONALITY

The $F$ test (Adorno et al 1950), a Likert-style scale, was devised to measure the right authoritarian rigidity that the authors felt was intrinsically related to ethnocentrism. Although there are no items on the $F$ test which relate specfically to ethnic groups, the test was designed so that the content of the attitude statements on the test was ideologically slanted in a direction similar to the content of those statements on the $E$ test. Not surprisingly, the valid- 
ity of the $F$ test was based upon positive statistical correlation with the $\mathrm{E}$ test.

Rokeach eventually refined his generalized mental rigidity theory so that the rigidity concept was later interpreted as a closed belief system. Closed, or dogmatic, thinking refers to "resistance to change of total belief system (Rokeach 1960, p. 193). The motivation for dogmatic thinking is the "need to ward off threatening aspects of reality" (ibid. p. 69), i.e. a defensive reaction.

The Dogmatism Scale, which also uses the Likert format, was designed "to measure individual differences in openness or closedness of belief systems" (ibid. p. 71). For all 40 items on the final version of the test, agreement with the item was scored as closed and disagreement as open. Thus, an ethnocentric person would be one who indicated strong agreement with many closed, or negative, statements.

The Opinionation Scale (ibid.) was similar in format and number of items to the Dogmatism Scale. It was dissimilar in that subjects responded to items on the Opinionation Scale such that they not only rejected or accepted a particular belief, but they reject or accept people who have that belief. Also, whereas the items on the Dogmatism Scale are concerned strictly with the structure of beliefs, the items on the Opinionation scale "must end up with some sort of content" (ibid. p. 81). Therefore, half of the items are worded in such a way that agreement with them expresses left authoritarianism and half are worded 
such that agreement with them expresses right authoritarianism. From the use of this scale as an ethnocentrism test, ethnocentrism has come to be seen as part of either a left or right authoritarian ideology.

The validity for the Dogmatism and Opinionation Scales was shown in two ways. First, high scorers on these scales also received high scores on the $E$ and $F$ tests. Secondly, the method of known groups was used, in which several graduate students gave the experimenters names of friends and peers who the graduate students felt were either high dogmatic or low dogmatic thinkers. The mean of the scores for the high dogmatic thinkers was, indeed, over fifty points higher than the mean of the scores for the low dogmatic thinkers (ibid. p. 104).

The Gough-Sanford Rigidity Scale, also labeled the California $F_{x}$ (Flexibility) scale, is a 22-item, Likerttype test. It was used by Rokeach (ibid. ch.9) in an attempt to show that even though rigid and dogmatic thinking characterize ethnocentrism, they are, nonetheless, discriminable processes: a dogmatic individual has difficulty thinking synthetically, but not analytically; a rigid individual has difficulty thinking analytically, but not synthetically. Still, Rokeach found the product-moment correlation between this scale and the Dogmatism Scale to be as high as .55 (ibid. p. 193). 


\section{SUMMARY}

In this chapter, I have discussed several tests which are representative of the scales used in the past thirty years to measure ethnocentrism. The tests are divided into two broad categories: 1) those concermed with attitudes toward other groups, and 2) those concerned with attitudes expressing a rigidity factor of the personality. The designers of all of these tests have been influenced by the four traditional aspects of ethnocentrism. As a result, on every one of these tests, negative feelings are associated with ethnocentrism, and the negative feelings are most commonly portrayed on the tests as attitude statements. I have made the point that ethnocentrism is not an attitude, nor is it necessarily associated with negative feelings. The relationship between ethnocentrism and attitudes is this: attitudes, either positive or negative, toward other people, as well as attitudes expressing rigid thinking, are all possible results of an ethnocentric perspective. My main criticism of these tests is that they do not attempt to capture the nature of this ethnocentric perspective. Our understanding of ethnocentrism has been diluted by the various synonyms used by the test designers for the ethnocentrism they are ostensibly measuring: in the first category, 'prejudice', 'social distance', 'nationalism', 'intolerance', 'anti-worldmindedness'; in the second category, 'mental rigidity', 'dogmatism', 'opinionation', 'authoritarianism'. 
This confusion of ethnocentrism with other terms has, at the worst, identified ethnocentrism erroneously, and at the best, merely broadened the periphery of our understanding of ethnocentrism without getting at the core. 


\section{CHAPTER VI}

ETHNOCENTRISM AND THE NEED FOR THE REFERENCE GROUP CONCEPT

THE BASIS FOR SETTING A PERCEPTUAL FRAMEWORK

In chapters two and three, I pointed out that the main value of the reference group concept, as perceived by reference group theorists, is its flexibility in portraying individual-group relations. However, as I further pointed out, these theorists tend to emphasize the reference group, at the expense of the individual, as the prime mover in individual-group relations. That is, they fail to view reference group orientation as a bi-directional, interactional process.

In this chapter, I will discuss, first, a basis in the literature for connecting the reference group concept and ethnocentrism. Secondly, I will maintain that where this connection has been made, reference group orientation is not seen as a bi-directional process. Moreover, the objective in making this connection is to show that ethnocentrism is not, as Sumner claimed it was, a universal phenomenon. And finally, I will suggest that the relationship between reference group orientation and ethnocentrism is, indeed, potentially an extremely useful one to investigate. 
As I've developed in previous chapters, both ethnocentrism and reference group orientation are perceptual processes. They can be placed in a similar framework in which, first, reference group orientation is defined as a person's use of a frame of reference formed through adoption of a reference group's perspective. Second, ethnocentrism is defined as a person's use of a frame of reference, which then keeps him from accepting any other frames of reference. The reason for bringing them together into the same theoretical framework is to discover whether there are some aspects in the nature of an individual's adoption of a reference group's perspective which will indicate why that individual would deny or accept the viability of other frames of reference.

\section{ETHNOCENTRISM AND REFERENCE GROUP THEORY}

When Sumner advanced his hypothesis about ethnocentrism he made the distinction between ingroups and outgroups, in which ingroups refer to a person's membership groups and outgroups refer to everybody else, i.e. other groups. He made the further assertion that the feeling of belongingness toward one's ingroup and the feeling of hostility toward one's outgroup "are correlative to each other" (Sumner 1906, p. 13). This assertion was based upon numerous illustrations from history and ethnology. One example that Sumner listed was that of the Greenland Eskimo, who thought that "Europeans had been sent to 
Greenland to learn virtue and good manners from the Eskimos" (ibid. p. 14); another example was that of the Seri of Lower California who "observed an attitude of suspicion and hostility to all outsiders" (ibid. p. 14). Also, he claimed that "the Greeks and Romans called all outsiders 'barbarians', and the Arabs regarded themselves as the noblest nation and all others as more or less barbarous" (ibid. p. 14). Sumner was very definite about the universality of these kinds of sentiments, claiming "Each state now regards itself as the leader of civilization, the best, the freest, and the wisest, and all others as inferior" ibid. p. 15) .

However, more recent anthropological evidence has been cited to show that ingroup acceptance/outgroup rejection does not characterize all of the world's societies (LeVine \& Campbell 1972, ch. 5). Many traditional societies, as well as many modern industrial societies, are not characterized by feelings of hatred for other groups that are caused by having feelings of loyalty toward a membership group. According to LeVine \& Campbell's discussion, it is suspect to base a definition of ethnocentrism upon the ingroup acceptance/outgroup rejection distinction for two reasons. First, individuals do not necessarily feel hatred for their 'outgroups'. In fact, this feeling of antipathy is quite often aimed toward one's original 'ingroup'. 'Cargo cults', 'nativistic movements', 'messianic movements' are all listed as examples of "conscious and organized dis- 
satisfaction with ingroup culture" (ibid. p. 65). Secondly, many individuals are not limited to one 'membership group' for all situations. That is, the social structure provides each individual with 'multiple memberships' (ibid. p. 67).

For these two reasons, the authors suggest that, instead of using terms such as 'ingroups', 'outgroups', and 'membership groups' for describing human relations, a more accurate way to consider ethnocentrism is in terms of reference groups. Their objectives are to show that 1) there are certain conditions under which outside groups, rather than membership groups, become reference groups, and that 2) the individuals who select these outside groups as positive reference groups are not very ethnocentric.

However, in their discussion, reference group orientation is not seen as an interactive process. Since their emphasis is on non-membership groups, or outside groups, becoming reference groups for individuals in various societies, the reference groups are considered simply as points to which individuals can refer. How the individuals perceive themselves through those reference groups' eyes is ignored. Thus, the authors are actually taking into account only one direction of a bi-directional process.

\section{CONCLUSION}

LeVine and Campbelf present a convincing argument that ingroup acceptance/outgroup rejection does not re- 
flect individual-group relations in the world's societies today. However, the authors do not conclude, as I have done, that the ingroup acceptance/outgroup rejection distinction should, therefore, be suspect as an aspect of ethnocentrism. In chapter five, I pointed out that an individual, even though he had accepted another group's standard or rejected their own group's standard, could still be ethnocentric.

In the same chapter, I also pointed out that a very illuminating depiction of ethnocentrism and ethnorelativism comes from placing them in a perceptual framework. The utility of placing ethnocentrism and ethnorelativism in a perceptual framework is enhanced by the fact that reference group orientation, as a bi-directional, interactive process, may be placed in a perceptual framework as well. Their common portrayal has not been made haphazardly. Examining reference group orientation offers an opportunity to understand one basis for ethnocentrism, since all of us adopt frames of reference when we, for example, begin a conversation, or watch television, or write a letter, or state an opinion, or laugh at a joke, or make a mistake. These frames of reference come from setting up and imagining responses from our reference groups. For some of us, only one reference group may be used, such as one's family. For others, reference groups may be quite diverse, or even vague, depending on the circumstance. The need for the reference group concept arises with re- 
spect to ethnocentrism because in the diverse manner with which we orient ourselves to our reference groups, and thus adopt their perspectives, there lies a source for discovering why people are ethnocentric or ethnorelative. In the next chapter, I hope to show why this is the case. 


\section{CHAPTER VII}

\section{THE RATIONALE FOR STATING THAT ETHNOCENTRISM AND ETHNORELATIVISM ARE BASED UPON REFERENCE GROUP ORIENTATION}

In this chapter, I will explain why we would gain further understanding of ethnocentrism and ethnorelativism by examining certain aspects of reference group orientation. After the theoretical model has been fully developed, I will generate some testable propositions which will help us to discover whether or not the connection between ethnocentrism/ethnorelativism and reference group orientation is a useful one.

THE ROLE OF THE FORMATION OF CULTURAL IDENTITY

I will begin the chapter by introducing the concept, 'cultural identity'. Cultural identity, here, refers to the identity of an individual as he relates to his culture (Adler 1976, p. 365). It is an important concept because the perceptual process of reference group orientation that I have presented in this thesis is a major component of the formation of a cultural identity. That is, a cultural identity manifests itself as the "names which locate and differentiate the person" (ibid. p. 366). The person's 'I' and 'me' form the names into potential reference groups. The ' $I$ ' expects a response and, immediately, the 
'me' imagines what that response will be. At that moment, she sees herself and others through the eyes of the names, or labels, that she uses for reference groups. By calling herself, for example, a 'female', a 'Buddhist', a 'mother', she is "symbolizing parts of the complex of images she has of herself and that are likewise recognizable by others" (ibid.). In other words, she perceives the world through the perspectives of her reference groups: 'females', 'Buddhists', 'mothers'.

The perceptual mechanism used by ethnocentric and ethnorelative persons is part of an overall process of constructing reality. An ethnorelative person, because she accepts not only her frame of reference but is willing to accept other frames of reference as well, constructs a world of multiple realities. An ethnocentric person accepts only one frame of reference, her own. That is, she constructs a single reality.

For every individual, cultural identity is the "image of the self and the culture intertwined in the individual's total conception of reality" (ibid.). For an individual with a single-reality perspective, the images of his cultural identity are fixed. Those names which he has derived through interaction with other people in order to locate and differentiate himself are not apt to be altered. Such utterances as "I'm just a small-town boy at heart", or "Once a catholic always a catholic" are two examples of these unchanging self-images. For an individual with a 
multiple-realities perspective, the images of his cultural identity are capable of fluctuations. He symbolizes the images he has of himself in a non-rigid way. For example, a person who has always considered himself, with the help of other people, as a 'poor cook', may subsequently change to a vegetarian diet and consider himself, again with the help of the interaction of his 'I' and 'me', as an excellent cook. Another example is a person who, for many years of his life, had developed a self-image of a 'cat-hater'. Eventually, he changed his self-image to 'cat-lover', through having interacted with people who own cats and, ultimately, through owning a cat himself.

A construction of reality is based upon the nature of the boundary, either rigid or flexible, that one forms around his cultural identity. The nature of the boundaries is extremely important with respect to the ability to relate to other cultures. That is, the way in which an individual's cultural identity has been formed will be more or less helpful to that individual's assumption of other cultural realities. An assumption of a single cultural reality characterizes both an ethnocentric perspective and a fixed cultural identity. An assumption of many cultural realities characterizes both an ethnorelative perspective and a fluctuating cultural identity. We will find out later whether or not ethnocentric/ethnorelative perspectives are related to the formation of fixed/fluctuating cultural identities. 
ENCULTURATION: A BASIS FOR THE PERCEPTUAL PROCESS IN ETHNOCENTRISM

AND ETHNORELATIVISM

A further influence upon the formation of cultural identities is the fact that each individual is imprinted, or ingrained, with his culture. Some individuals' cultural identities are more indelibly imprinted with their culture than other individuals' cultural identities. The degree of the indelibility of one's culture upon his cultural identity is realized by a process which occurs throughout a person's life. This process of acquiring the culture into which one is born is called enculturation.

Enculturation has been termed a means by which "one achieves competence in their culture" (Herskovits 1948, p. 39). It has both a direct and an indirect effect. Its direct impact concerns the choices of behavior that a particular culture offers to its members. As these members grow up in their culture, they learn, through "conflict and cooperation with other members, direct reward and punishment, inhibition of actions, being blocked by others" ( $\mathrm{Se}$ gall et al 1966, p. 10), what kinds of behavior they have from which to choose. The indirect impact of enculturation has to do with the fact that those choices were the result of our being presented with only a single set of alternatives. That is, the vast majority of us experience, especially during the infancy to adolescence period, only one cultural setting. The limitation of not being aware of 
the other sets of alternatives that could have been available to us, and which can only be ascertained by having experienced other cultural settings, or a great deal of interaction with people from other cultural settings, is very subtly woven into the enculturation experience. The limitation stems from the inability to step out of an enculturation experience and, by taking a meta-perspective of it, to appreciate that this experience was not the only possible one.

The indirect impact of the enculturation experience $s$ the more powerful one, because of the effect it has on our perceptions of people who have grown up in other cultural settings. Typically, we fail to acknowledge that people undergoing other enculturation experiences have had available to them sets of alternative choices of behavior, attitudes, perceptions, learning styles, etc. In fact, the most enculturated individuals are the people who are least able to recognize that other people have been enculturated differently. Also, as Segall et al point out, "The most enculturated person is the least aware of his culture's role in molding him" (ibid. p. 11). Or, to restate this dual process in terms of the perceptual framework that I have been developing: an individual who is unaware of his om enculturation experience adopts a frame of reference which denies that people in other cultures organize their experiences differently. The basis for an ethnocentric perspective lies in the failure to recognize the limita- 
tions of an enculturation experience. This failure to recognize that one is wearing cultural blinders is akin to having a single-reality perspective.

I would like to offer the suggestion that where an individual's cultural blinders are removed and a multiplerealities perspective has been achieved, i.e. an ethnorelative position is apparent, the boundary of her cultural identity has shown a tendency to expand. That is, the names and labels that locate and differentiate her have been numerous and diverse. Since a perceptual process involved in the formation of a cultural identity is the orientation to reference groups, then one manner of having attained an expansion of cultural identity is through an increase in number and diversity of reference group orientations.

THE ENCULTURATION PROCESS AS REFERENCE GROUP ORIENTATION

Before discussing the number and diversity of reference group orientation, I will establish that the enculturation process can be explained in terms of reference group orientation. This can be illustrated by listing some kinds of reference group orientations that individuals, especialchildren, form in various cultures. For example, in the U.S., adolescence is a period of emotional turmoil in which youths are constantly reformulating their ties with other youths. Ultimately, the "consequences of identifying one- 
self with a particular set of people and with small groups within it are far-reaching" (Sherif \& Sherif 1964, p. 30). On the other hand, in Samoa, an adolescent girl's reference group orientations are not with girls her own age. Even before the onset of puberty, a Samoan girl, in matters other than fertility, comes to be perceived as, and to behave like, a woman (Benedict 1934, p. 30). Papago Indian children take on adult perspectives even earlier than Samoan giris. At the age of three or four, a Papago child spends much of his playtime trying to emulate the adults around him (Williams 1972, p. 57). In Senegal, boys begin to form age-groups at about the age of three or four. A few years later, the frame of reference of a Senegalese boy's' agegroup will become even more strongly his own, since other similarly-aged boys are the ones with whom he will share the rigors of undergoing a circumcision rite. In Ghana, Ashanti children must learn about the formal group configuration of their culture so that they can understand their position within it. Soon they come to adopt the perspectives of other people who are, for example, from similar rank, of similar occupation, or with similar income (ibid. p. 151). Thus, in the U.S., an adolescent boy's reference groups could be, for example, 'other boys in the neighborhood', or 'students who get all "A's" in school'. In Samoa, an adolescent girl's reference group might be her 'older sister and older girl-cousins who are of marrying age'. An early reference group for a Papago Indian boy may 
include his father and uncles. A Senegalese boy at age ten will probably have a strong reference group orientation with 'similarly-aged boys of his ethnic group'; and perhaps, secondarily, with 'similarly-aged boys from other ethnic groups in that region of Africa'. A fourteen year old Ashanti girl of noble rank, whose mother and older sisters married rich landowners and have several domestic servants in their compounds, will undoubtedly orient herself to reference groups comprising 'women who will have rich husbands of high rank', or 'women who will oversee the domestic chores of a household'.

THE NATURE OF THE FORMATION OF CULTURAL IDENTITY

The formation of a cultural identity begins in childhood. How a child is reared by his parents helps determine whether this formation will transpire in a rigid or a flexible way.

For one individual, say a young American male, the images that he has formed of himself, for example, 'male', 'Christian', 'a bully at school', 'respectful of authority', may have been formed so absolutely at an early age that they have remained fixed. That is, his parents may have insisted that when he was a child, he should conform closely to what they felt were the standards in their society. Thus, the names and labels from which he could draw, in order to form his self-image, were limited.

This limited range of self-images, used to form his 
cultural identity, is dependent upon various characteristics "which have previously been identified as being related to the authoritarian personality syndrome" (Thomas 1975, p. 236). Thus, for example, the authoritarian characteristic, in the young American male's parents' childrearing practices, of having "high demands for the child to retaliate to aggression from peers" (ibid. p. 236), may be the source for his rigidly formed self-image of being a 'bully at school'. Or the authoritarian characteristic, that his mother had, of "expecting immediate obedience from her children" (ibid.), might have led him to see himself as being extremely 'respectful of authority'. Another authoritarian characteristic was his parents' insistence on a "high degree of sex role differentiation in training their children" (ibid.). His strongly developed 'male' selfimage may have been the result of this characteristic. Finally, the authoritarian characteristic, that his parents had, of "believing in the effectiveness of physical punishment" (ibid.), and their "non-permissiveness of sexual behavior (nudity, masturbation, sex play)" (ibid.), may have led him to see himself as a staunch 'Christian'.

As an adult, in his interaction with other people, he has a restricted number and kind of self-images to draw from. The reference groups to which he orients himself are few and are not apt to change their shape. Unless he attempts to expand his cultural identity, by, for example, developing a willingness, through his interaction with 
other people, to re-examine his self-images, he will remain unaware of how his cultural identity has been formed. Thus, he will remain unaware of his own enculturation experience. Finally, he will be hard put to recognize that there are other cultural realities.

Conversely, another young American male has been encouraged, or has encouraged himself, to keep the boundaries of his cultural identity open. His parents may not have used an authoritarian style while raising him. Consequently, he had a large array of images to choose from, and to have others help him choose. Throughout his life, he has remained open to other people's attitudes and perceptions of him. He has, from time to time, examined his self-images, and discovered, again through interaction with other people, that some of them needed adjustment. The boundaries of his cultural identity have been subject to fluctuation.

TWO ASPECTS OF REFERENCE GROUP ORIENTATION: (1) MULTIPLICITY AND (2) STRUCTURAL VARIATION

Multiplicity of reference group orientation refers to the number of reference groups that a person is aware of using. This aspect of reference group orientation concerns all the reference groups whose perspectives he perceives, and which could have existed in the past, exist presently, or may exist in the future. The reference groups may be real only for the person who is using them, or they may be much the same ones as another person uses. Examples of ref- 
erence group orientation that might be included in a discussion of multiplicity are the following: 'heads of households', 'good providers', 'executives', ex-football players', 'hard workers', 'persons with many good friends', 'Catholics', 'not-so-loving husbands', 'high-priced pencil pushers', 'impatient persons', 'responsible citizens', 'opera lovers', 'volunteer literacy tutors'.

Structural variation of reference group orientation refers to the amount of variation in the structure, or makeup, of reference groups that a person is aware of using. As I suggested in the last section, there is a link between 1) the kinds of social interactions that a person has had, especially during the early years of enculturation, 2) the formation of his cultural identity and 3) the structural variation of his reference groups. That is, a person with low structural variation of reference group orientation has been rigidly fixed into his cultural identity. As a child, his parents probably helped him to set very definite limits and conditions for orienting himself to reference groups. When he orients himself' to a reference group comprised of, for example, 'workers', it is relatively as easy for him as it is for others to identify those people who would be included in this reference group. On the other hand, a person with high structural variation has not been rigidly fixed into his cultural identity. His parents may have taken a smaller role in defining the parameters of his reference groups. Or they, and/or later significant others, may have helped him 
to set indefinite limits and conditions for orienting himself to reference groups. When he orients himself to a reference group such as, for example, 'hard workers', the limits and conditions for orientation to this reference group are more subjective than they are for the reference group 'workers'. It is not obvious to other people, and perhaps not even to the person who is orienting himself to the reference group, 'hard workers', who should be included in it.

Some further examples illustrating the distinction between high and low structural variation of reference group orientation are the following: Instead of an orientation to a reference group which simply includes 'husbands', a higher structural variation of reference group orientation might be to 'loyal mates'. Or, instead of the reference group 'mothers', one may orient to 'those who are going to be grandmothers someday'. Or, instead of the reference group 'students', one may orient himself to 'fairly intelligent persons'. Or, instead of simply, 'persons', one may orient herself to 'honest persons', 'unpretentious persons', 'supportive persons', 'conscientious persons', 'happy persons', and so on.

\section{CONCLUSION}

The powerful indirect impact of the enculturation process is apparent with respect to the contrasts in kinds of reference group orientation. That is, it is unlikely that 
a Samoan girl will be aware of the possibility of adopting the perspective, during adolescence, of anyone other than adults. It is also unlikely that a Senegalese boy will be aware of the fact that boys his age in some parts of the world are used to having reference groups based upon other than age-sex similarities. Again, in terms of the perceptual framework presented in the thesis, I can restate the process in this way: the person who is aware of a low multiplicity and structural variation of his own orientation to reference groups, will be least aware of the frames of reference of people in other cultures, i.e. of the viability of those persons' reference groups' perspectives.

Moreover, the claim has been made in the literature that ethnocentrism is rooted in the early years of enculturation (Adorno et al 1950, pp. 281-389; Caditz 1976, p. 633; Thomas 1975, p. 235). Specifically, some authoritarian child-rearing practices, during early enculturation, have been identified as contributing to ethnocentrism (Thomas 1975, p. 235). I have suggested that the dimension of authoritarian/non-authoritarian child-rearing by parents is directly related to the dimension of rigid-flexible development of self-images by children in the formation of their cultural identities. Since a person's use of selfimages is the basis for his reference group orientations, the rigid-flexible development of self-images can also be stated in terms of the 1) multiplicity and 2) structural variation of reference group orientations. 
CHAPTER VIII

HYPOTHESES

From the foregoing theoretical framework, the following hypotheses may be drawn:

(Theoretical hypotheses):

1) Those people who are aware of their own enculturation experiences are more likely to be aware that there are other enculturation experiences than those people who are not aware of their own enculturation experiences. 2) Those people who are aware of their own enculturation experiences and the formation of their own cultural identities are more likely to accept the viability of other cultural frames of reference than those people who are not aware of their own enculturation experiences and the formation of their own cultural identities.

(Research hypotheses):

1) Those people who are aware of a relatively high multiplicity in their reference group orientations are more likely to accept the viability of other cultural frames of reference than those people who are aware of a relatively low multiplicity in their reference group orientations.

2) Those people who are aware of a relatively high structural variation in their reference group orientations 
are more likely to accept the viability of other cultural frames of reference than those people who are aware of a relatively low structural variation in their reference group orientations.

(Operational hypotheses):

1) There will be a direct correlation between high/low "multiplicity of reference group orientation" scores on the "Who are you?" test and high/low scores on the "Acceptance/ rejection of other cultural frames of reference" test. 2) There will be a direct correlation between high/low "structural variation of reference group orientation" scores on the "Who are you?" test and high/low scores on the "Acceptance/rejection of other cultural frames of reference" test. 
CHAPTER IX

PILOT STUDY

PURPOSE OF THE PILOT STUDY

The objective of this pilot study is to test the two research hypotheses in the previous chapter. To this end, I have, first, adapted the "Who am I?" test (Kuhn \& McPartland 1954) to form a test in which subjects must utilize the interactional process described in this thesis in order to identify their reference group orientations. This adapted version has been named the "Who are you?" test (See Appendix A). Secondly, I have devised five questions, using a semantic differential technique, which pertain to aspects of ethnocentrism/ethnorelativism. This has been called the "Acceptance/rejection of other cultural frames of reference" test (See Appendix B).

The purpose of the pilot study is twofold. First, I want to see if the first test can discriminate among populations with respect to the awareness of one's own multiplicity and structural variation of reference group orientation. Secondly, I want to check for a degree of association, using the Pearson ' $r$ ' coefficient, between responses for the two tests. 
THE "WHO AM I?" TEST AND THE "WHO ARE YOU?" TEST

The "Who an I?" test consisted of a sheet of paper with these instructions:

There are twenty numbered blanks on the page below. Please write twenty answers to the simple question "Who am I?" in the blanks. Just give twenty different answers to this question. Answer as if you were giving the answers to yourself, not to somebody else. Write the answers in the order that they occur to you. Don't worry about logic or 'importance'. Go along fairly fast, for time is limited (ibid. p. 114).

Like the authors of this test, I feel that this "self-identification" is an effective way of having subjects place themselves "within the range of possible reference groups" (ibid. p. 118). However, to be consistent with symbolic interactionism, from which the concept 'reference group' developed, the identification of one's reference groups must be a bi-directional process. That is, it is impossible to consider an individual's selection of his reference groups without some consideration of the reference group's selection of the individual. These two processes are interactive and the resulting reference group orientation produces a perceptual filter or frame of reference for the individual.

The "Who are you?" test consists of two parts. The first part, for which the directions are in Appendix $A$, appears to the subjects to be the entire test. However, at the end of the seven minutes, the experimenter then gives directions for the second part, saying, "Now, go back 
and put a check mark after a response if you feel that other people think of you this way also. You will have five minutes."

In adapting the "Who am I?" test, I have, so as to avoid confusion, changed the question to "Who are you?". Also, I have put as many lines on the page as possible, since one of the things I'm looking for is multiplicity of response. The question asked by the experimenter is essential in order that the reference groups identified on the test fit the theoretical framework set out earlier in the thesis. That is, a response has been considered a reference group orientation for a subject only if she has placed a check mark beside that response. For each subject, a raw score has been, thus, derived which consists of all the responses having check marks beside them. This raw score constitutes the "multiplicity of reference group orientation" score.

Structural variation is the other aspect of reference group orientation about which subjects have responded. The dichotomous categorization technique used in the "Who am I?" test has also been used here in order to determine a raw score that consists of structurally varied, i.e. imaginative or diverse, reference group orientations. That is, Kuhn and McPartland divided responses to the "Who am I?" test into 'consensual' and 'subconsensual' references. A 'consensual' reference is that which refers to "groups and classes whose limits and conditions of membership are mat- 
ters of common knowledge" (Kuhn \& McPartland 1954, p. 115). The authors include such examples as 'student', 'girl',

'Baptist', 'from Chicago', 'oldest child', 'husband',

'studying engineering'. A 'subconsensual' reference is that which refers to "groups, classes, attributes, traits or any other matters which would require interpretation by the respondent to be precise or to place him relative to others" (ibid.). Examples from their study include 'happy', 'bored', 'pretty good student', 'too heavy', 'good wife', 'interesting' .

In other words, structural variation of reference group orientation, like 'subconsensual' references, indicates the degree of variation in self-identifications. The "structural variation of reference group orientation" score for each subject, then, consists of all the responses having check marks beside them, that are also 'sub-consensual'.

THE "ACCEPTANCE/REJECTION OF OTHER CULTURAL FRAMES OF REFERENCE" TEST

The "Acceptance/rejection of other cultural frames of reference" test is based upon the explanation of ethnocentrism and ethnorelativism found in this thesis. Three of the five questions (nos, 2, 3 and 5) concern significant aspects of ethnocentrism and ethnorelativism:

(2) the assumption of cultural similarity and the assumption of cultural difference, (3) the acceptance or denial 
of the viability of other frames of reference, and (5) the utilization or non-utilization of a frame of reference which denies the viability of other cultural frames of reference. The first question concerns a philosophical basis for having an ethnocentric or ethnorelative perspective: the construction of a single reality or multiple realities. One question (no. 4) concerns the ability or nonability for empathy. I have included this question with an aim to finding out whether or not empathy is related to an ethnorelative perspective. The five questions, taken together, are representative of the notions of ethnocentrism and ethnorelativism.

The seven-point semantic differential allows for a broad range of responses. In two of the questions (nos. 2 and 4), ethnocentric and ethnorelative ends of the scale have been reversed to avoid a response set on the part of subjects. The raw score for this test is found by totalling the numbers ' $X$ '-ed for each question and dividing by five, with question nos. 2 and 4 rescaled accordingly. This raw score constitutes the "acceptance of other cultural frames of reference" score.

\section{RESULTS AND DISCUSSION OF THE PILOT STUDY}

The subjects for the two tests comprising this pilot study were twenty-one undergraduate students from a speech Communication class at Portland State University. Since it was an evening class, the range of subjects' ages appeared 
to be fairly broad. Thus, a more representative sample of the general population than merely 'college-aged individuals' is represented in the study. Twelve women and nine men took part in the study. Fifteen of the respondents were American and six were International students.

The results of the pilot study which are of most concern to this thesis are found in Tables I and II. In Table I, the raw scores for "multiplicity of reference group orientation" (M), "structural variation of reference group orientation" (SV), and "acceptance of other frames of reference" (ACFR), are listed in columns three, four and five, respectively. Raw scores from the "Who are you?" test suggest that the first purpose of the pilot study has been achieved. That is, with ' $M$ ' scores ranging from four to thirty-three, and with 'SV' scores ranging from zero to twenty-six, the test appears to be able to discriminate among populations with respect to the awareness of one's own multiplicity and structural variation of reference group orientation. In column two, I have indicated the sex of each subject. In column one, I have indicated, by an asterisk, those subjects who are International students. In selecting the responses that are sub-consensual, and therefore included in the 'SV' raw scores, there is an element of subjectivity involved. Thus, a panel of three judges has served as an external objective criterion for the dichotomous categorization of all reference group responses as 'consensual' or 'subconsensual'. Discrepancy in agree- 
ment between judges was slight, occurring for all categorized responses in the following percentages: $2.63 \%$ between judges one and two; $6.06 \%$ between judges one and three; $5.54 \%$ between judges two and three.

\section{TABLE I}

\section{RAW SCORES}

\begin{tabular}{ccrrr} 
Subjects & Sex & $\frac{M}{\text { M }}$ & $\underline{\text { SV }}$ & $\underline{\text { ACFR }}$ \\
\cline { 1 - 3 } 1* $^{*}$ & F & 18 & 4 & 4.0 \\
$2^{*}$ & $\mathrm{M}$ & 6 & 0 & 6.0 \\
4 & $\mathrm{M}$ & 25 & 14 & 4.6 \\
$5^{*}$ & $\mathrm{~F}$ & 28 & 10 & 6.8 \\
6 & $\mathrm{M}$ & 18 & 16 & 5.2 \\
7 & $\mathrm{~F}$ & 23 & 0 & 4.4 \\
8 & $\mathrm{~F}$ & 21 & 11 & 5.4 \\
9 & $\mathrm{M}$ & 10 & 1 & 4.0 \\
10 & $\mathrm{M}$ & 19 & 12 & 5.4 \\
11 & $\mathrm{~F}$ & 11 & 9 & 4.0 \\
$12^{*}$ & $\mathrm{~F}$ & 24 & 21 & 5.0 \\
13 & $\mathrm{M}$ & 19 & 9 & 3.6 \\
14 & $\mathrm{~F}$ & 13 & 9 & 4.0 \\
$15 *$ & $\mathrm{M}$ & 11 & 3 & 5.4 \\
16 & $\mathrm{~F}$ & 12 & 10 & 5.4 \\
$17^{*}$ & $\mathrm{~F}$ & 24 & 3 & 5.6 \\
18 & $\mathrm{~F}$ & 4 & 0 & 3.4 \\
19 & $\mathrm{M}$ & 24 & 11 & 5.2 \\
20 & $\mathrm{~F}$ & 21 & 17 & 6.4 \\
21 & $\mathrm{M}$ & 15 & 10 & 4.8 \\
& $\mathrm{~F}$ & 33 & 26 & 6.2
\end{tabular}

In Table II, the degree of association between the two tests is indicated. In the top half of Table II the overall measure of correlation of the study is indicated, with all the subjects included for the figures in the first row, and all the International students excluded for the figures in the second row. Results suggest that a moderately positive correlation (.47) exists between multiplicity of reference group orientation and the acceptance of 
other cultural frames of reference. Only a slightly less positive correlation (.41) exists between structural variation of reference group orientation and the acceptance of other cultural frames of reference. In the bottom half of Table II, the figures in each row indicate the degree of association between each question on the "Acceptance/rejection of other cultural frames of reference" test and multiplicity and structural variation of reference group orientation. Only question no. 2 shows low Pearson ' $r$ ' values in both columns. I suggest that there are two possible reasons for this, given the moderate success of the other questions in reflecting an ethnocentric/ethnorelative differential. Either the question is too wordy, or even otherwise ethnorelative folks are premature in their desire to assert some basic similarity among all people. Finally, the results from question no. 4 are inconclusive regarding the positive relationship between empathy and ethnorelativism.

A relatively high percentage (29\%) of the subjects in this study were International students. Information about the length of time spent by these students in the U.S. and their level of English ability was not obtained. Although the format of the tests may have been more familiar to the American subjects, unfamiliarity with the content of the tests was comparable for all subjects. Every subject understood the directions for both tests. However, the International students may not have had sufficient English 
skills to respond as loquaciously as the American students to the "Who are you?" test. Moreover, it is unknown whether or not multiplicity and structural variation of reference group orientation can be used as cross-cultural constructs. Thus, in the top half of Table II, a separate listing of Pearson ' $r$ ' values is given for 'Americans only'.

\section{TABLE II}

DEGREE OF ASSOCIATION BETWEEN THE "WHO ARE

YOU?" TEST AND THE "ACCEPTANCE/REJECTION OF OTHER CULTURAL FRAMES

OF REFERENCE" TEST

Total

population

Americans

only
Correlation between ' $M$ ' and 'ACFR'
Correlation between 'SV' and 'ACFR'
.47

.59
.41

.41
Correlation between ' $M$ ' and each 'ACFR' item

ACFR (1)

ACFR (2)

ACFR (3)

ACFR (4)

ACFR (5)
.38

.06

.52

.13

.36
Correlation

between 'SV' and each 'ACFR' item

$-.09$

.09

.38

.38

.38

\section{CONCLUSION}

Results of the pilot study illustrate that the two purposes of the study have been, in the first case, successfully, and in the second case, somewhat successfully, attained. First, the "Who are you?" test has been able to 
discriminate among populations with respect to subjects' awareness of their own multiplicity and structural variation of reference group orientation. Secondly, a moderate degree of association appears to exist between the acceptance of other cultural frames of reference and high multiplicity and high structural variation of reference group orientation.

Based upon the results of the pilot study, the following conclusions concerning future research in this area may be drawn:

(1) Further experiments should be carried out testing the validity of multiplicity and structural variation of reference group orientation as aspects of ethnocentrism and. ethnorelativism.

(2) If the "acceptance/rejection of other cultural frames of reference" is to be the construct for ethnocentrism and ethnorelativism, then the questions on a test should reflect this construct as precisely as possible. Questions which pertain directly to ethnocentrism and ethnorelativism, such as nos. 3 and 5 in the present test, should be used.

(3) The very similar levels of correlation show in this study for a population comprised only of Americans, and a population comprised of Americans and Internationals, might suggest the utilization of the aspects, "multiplicity and structural variation of reference group orientation", as 
cross-cultural constructs. However, further experimentation should be carried out in culture-specific testing situations before this similarity may be adjudged anything but mere coincidence. 


\section{CHAPTER X}

\section{APPLICATIONS}

In this chapter, I would like to make two applications of the perceptual model for ethnocentrism and ethnorelativism that was developed in the thesis. First, I will apply the aspect of denying or accepting the viability of other cultural frames of reference to one field of TESOL: teaching English as a second language. Secondly, I will suggest that the awareness of the reference groups of people in target cultures could be an effective avenue for training of people who are going to. live and work abroad.

\section{TEACHING ENGLISH AS A SECOND LANGUAGE}

Teachers of ESL (English as a second language) teach English in the U.S. to students whose language background has not included, or included only minimally, English instruction. Also, in one ESL classroom, there may be students from several different cultural backgrounds. Moreover, the students' cultural backgrounds often have not prepared them for the types of classroom behavior and interaction with other students that their American teachers demand of them.

ESI teachers must be aware that these students are bringing learning strategies and classroom behavior which 
are based upon the learners' cultural conditioning. In other words, the teachers must be prepared to accept frames of reference which are different from those of learners in the teachers' own culture.

Part of an ESL teacher's pedagogical training should include an infusion of sensitivity to the culturally diverse classroom behaviors that he may confront. Moreover, it would be desirable, though not essential, to have an understanding of the perceptions and values which underlie these behaviors. One major step toward increasing the cultural sinsitivity of ESI teacher-trainees is to inform them that there is a plethora of potential cultural frames of reference among ESI students, and the teacher should at least be in a position in which he accepts their viability. To this end, the primary goal is to recognize classroom behavior that is based upon cultural frames of reference other than the teacher's own frame of reference. In each case of such classroom behavior that the teacher is able to recognize, his first reaction should be to refrain from using his own frame of reference long enough to realize that another cultural frame of reference is being used. For example, when an ESL teacher is speaking to a Mexican student and the student refuses to look at the teacher, the teacher should be prepared to at least withhold his own frame of reference, which says, "This student is showing disrespect." The teacher may or may not understand the behavior, but he will, by accepting the viabil- 
ity of that student's frame of reference, uphold his side of a relationship which is conducive to the student's learning English. Another example is the teacher who calls upon a Hmong female student and gets a response which is either aided or influenced by the Hmong males around her. If the teacher doesn't insist that the girl respond with no help from the males around her, he will have more effective subsequent classroom interaction with her.

Sometimes, effective interaction between an ESL teacher and student fails to develop because the teacher is unaware of perceptions or values, rather than outward behavior, on the part of a student that require the teacher's acceptance of another frame of reference. That is, the teacher continues to utilize his frame of reference, and is not even cognizant that it is appropriate to drop that frame of reference. For example, American ESL teachers should be aware that, quite often, the informality and casualness in their teaching style may be confusing to students who are not used to such behavior from their teachers. Students, in turn, may begin to respond to this informal atmosphere by behaving in, what they assume to be, appropriate ways, yet which are unsuitable from the perspective of the teacher: by speaking out of turn during class, by coming late to class, by coming to class without necessary supplies. The result may be a poor relationship between the teacher and students.

In summary, an ESL teacher will become a more effec- 
tive instructor of English if she, first of all, is prepared to manage a classroom of cultural diversity. By having the willingness and the ability to accept the viability of a vast array of cultural frames of reference within a classroom setting, the teacher will develop a better rapport with her students than if she didn't have that willingness or ability. As a result, the students will be comfortable with their teacher and increase their English skills rapidly.

OVERSEAS TRAINING: AWARENESS OF ALTERNATIVE REFERENCE GROUP ORIENTATIONS

One of the most important targets for overseas training is a preparation for those occasions in which the "strangeness of life in a foreign country (can) lead to uncertainty" (Stewart 1972, p. 79). Also, according to Kohls, one of the most essential skills for Americans, and undoubtedly others as well, to have overseas is a tolerance for ambiguity (Kohls 1979, p. 72). A major source of this uncertainty or ambiguity is the over-reliance upon familiar cultural frames of reference in situations for which these frames of reference are inappropriate: expressing an opinion at the wrong time, neglecting to shake hands when one should have, misjudging the meaning of a smile, or misinterpreting an intended meaning of punctuality. The use of an individual's own cultural frame of reference may, at first, feel comfortable for him because it helps to "dispel 
the ambiguity created by the unusual behavior of foreigners" (Stewart 1972, p. 79). However, in the long run, the use of one's own cultural frame of reference as the only natural one, will lead to frustration and uncertainty in how to function in that culture.

One of the causes of frustration and confusion in another cultural setting is that one is deprived of familiar cultural cues which allow him to act, or to make judgment without thinking. Another way of viewing this deprivation is that the orientation to reference groups to which he is accustomed is not reinforced through his interactions in the new culture. One way of overcoming the frustration, and thus, the uncertainty, of dealing with another culture is to become aware of the orientations to reference groups which commonly exist for members of that culture. For example, a common characteristic of the reference groups to which Americans orient themselves, based upon some examples from the "Who are you?" test, is that they can often be described as 'doers', 'hard workers', 'gardeners', 'skiers', 'tennis players', 'hunters', 'pizza makers', 'runners'. It might be very useful for an American, who perceives himself mainly as a 'doer', and who is about to take an overseas position, to know that most people in his host country do not orient themselves to 'doer'-type reference groups. Rather, their reference groups might be those in which qualities of people are paramount: 'talkative persons', 'thoughtful persons', 'patient persons', 'family- 
oriented persons', 'thin persons'.

Another characteristic of the responses from the "Who are you?" test is that most Americans failed to mention that they were 'Americans', or that, in fact, that they were from any particular state, city, town, neighborhood, etc. An American who did not consider reference group orientations based upon geographical roots as important, would find it extremely useful to know that most people in a culture in which he was about to live, had numerous reference group orientations pertaining to where they were from: 'small town persons', 'mountain-dwellers', 'persons from

Non-Americans who are about to spend time in the U.S., such as foreign students, would also benefit from knowledge of their target culture's typical reference group orientations. Americans quite often orient themselves to 'friendly persons', 'wonderful friends', 'true friends', 'loyal friends'. A newly-arrived International student should be made aware of many Americans' frequent orientations to 'friends', and thus, be prepared for people who might define 'friends' in a way different than he is used to.

In summary, the uncertain situations that people who live or work overseas find themselves in can be alleviated by increasing their understanding, before departure, of the people in the target culture. I suggest that making them aware of typical reference group orientations which exist in the target culture might be a useful way of preparing 
them for living in their new culture. As an item of instruction for overseas training, awareness of reference group orientations would be, for example, more easily understood, more readily digestible than the sometimes seemingly impenetrable system of values of a culture's members, and, for example, more beneficial than a description of behavior. 


\section{A SELECTED BIBLIOGRAPHY}

Adler, P. "Beyond Cultural Identity: Reflections on Cultural and Multicultural Man." Intercultural Communication: a Reader. 2nd ed. Ed. L.A. Samovar and R.E. Porter. BeImont: Wadsworth Publishing Co., Inc., 1976.

Adorno, T.W., et al. The Authoritarian Personality. N.Y: Harper and Brothers, 1950.

Benedict, R. Patterns of Culture. Boston: Houghton Mifflin Co., 1934.

Berger, $P$. and Luckmann, $T$. The Construction of Social Reality; a Treatise in the Sociology of Knowledge. Garden City: Anchor Books, 1967.

Block J. and Block, J. "An Investigation of the Relationship Between the Intolerance of Ambiguity and Ethnocentrism." Journal of Personality, 19 (1951), 303-11.

Bogardus, E.S. "A Social Distance Scale." Sociology and Social Research, 17 (Sept. 1932-Aug. 1933), 265-71.

Brown, R. "A Determinant of the Relationship Between Rigidity and Authoritarianism." The Journal of Abnormal and Social Psychology, $48(1953), 469-76$.

W Caditz, J. "Ethnic Identification, Interethnic Contact, and Belief in Integration." Social Forces, 53 (1976), $632-45$.

Cain, M. "Suggested Developments for Role and Reference Group Analysis." British Journal of Sociology, 19 $(1968), 191-205$.

Chang, E.C. and Ritter, E.H. "Ethnocentrism in Black College Students." The Journal of Social Psychology, 100 $(1976), 89-97$.

Clark, R.E. Reference Group Theory and Delinquency. N.Y: Behavioral Publications, 1972.

Cooley, C.H. Human Nature and the Social Order. N.Y: Charles Scribner and Sons, 1937.

Dubois, P.H. An Introduction to Psychological Statistics. 
N.Y: Harper and Row, 1965.

Frenkel-Brunswik, E. "Intolerance of Ambiguity as an Emotional and Perceptual Personality Variable." Journal of Personality, 18 (1949), 108-43.

Glazer, N. "Behind Today's Troubling Emphasis on Ethnic Origin." U.S. News and World Reports, 11 Jan. 1980, p. 63 .

Harding, J., et al. "Prejuaice and Ethnic Relations." The Handbook of Social Psychology. 2nd el. Vol V. Ed. G. Lindzey and E. Aronson. Reading: Addison-Wesley Publishing Co., 1969.

Hartley, R. "Norm Compatibility, Norm Preference, and the Acceptance of New Reference Groups." Readings in Reference Group Theory and Research. Ed. H.H. Hyman and E. Singer. N.Y: The Free Press, 1968.

Herskovits, M. Man and his Works; The Science of Cultural Anthropology. N.Y: A.A. Knopf, 1948.

Hyman, H.H. and Singer, E. "Introduction." Readings in Reference Group Theory and Research. Ed. H.H. Hyman and E. Singer. N.Y: The Free Press, 1968.

Hyman, H.H. and Singer, E. Readings in Reference Group Theory and Research. Ed.H.H. HYman and E. Singer. N.Y: The Free Press, 1968.

Kelley, H.H. "Two Functions of Reference Groups." Readings in Reference Group Theory and Research. Ed. H.H. Hyman and E. Singer. N.Y: The Free Press, 1968.

XKemper, T. "Reference Groups, Socialization and Achievement." American Sociological Review, 33 (1968), $31-45$.

Kohls, L.R. Survival Kit for Overseas Living. Chicago: Intercultural Network/Systran, 1979.

Kuhn, M.H. and McPartland, T.S. "An Empirical Investigation of Self-Attituaes." American Sociological Review, $19(1954), 68-76$.

Kuhn, M.H. "The Reference Group Reconsidered." Symbolic Interactionism; a Reader in Social Psychology. 2nd ed. Ed. J.G. Manis and B.N. Meltzer. Boston: Allyn and Bacon, 1972

LeVine, R. and Campbell, D.T. Ethnocentrism: Theories of 
Conflict, Ethnic Attitudes and Group Behavior. N.Y: Wiley, 1972.

Levinson, D. "Authoritarian Personality and Foreign Policy." Journal of Conflict Resolution, 1 (1957), 37-47.

Manis, J.G. and Meltzer, B.N. Symbolic Interactionism; a Reader in Social Psychology. 2nd ed. Boston: AlIyn and Bacon, 1972 .

Mead, G.H. Mind, Self and Society. Chicago: The University of Chicago Press, 1934.

Merton, R.K. and Rossi, A.K. "Contributions to the Theory of Reference Group Behavior." Readings in Reference Group Theory and Research. Ed. H.H. Hyman and E. Singer. N.Y: The Free Press, 1968.

Muhar, I.S. "Intercorrelations Amongst Six Measures of Rigidity." Indian Journal of Psychology, 49 (1974), 59-64.

Murdock, G. Encyclopedia of the Social Sciences. Ed. R.A. Seligman. N.Y: The Macmillan Co., 1937.

Newcomb, T.M. Social Psychology; the Study of Human Interaction. N.Y: Holt, Rinehart and Winston, 1960.

Novak, M. "Further Thoughts on Ethnicity." Christian Century, 90 (1973), 40-43.

Perlmutter, P. "The Troubling Future of Ethnicity." Christian Century, $94(1977), 718-21$.

Porter, R.E. and Samovar, I.A. "Communicating Interculturally." Intercultural Communication: a Reader. 2nd ed. Ed. I.A. Samovar and R.E. Porter. Belmont: Wadsworth Publishing Co., Inc., 1976.

Prentice, N.M. "Critique and Notes: the Comparability of Positive and Negative Items in Scales of Ethnic Prejudice." The Journal of Abnormal and Social Psychology, 52 (1956), 420-21.

Rokeach, M. "Generalized Mental Rigidity as a Factor in Ethnocentrism." The Journal of Abnormal and Social Psychology, 43 (1948), 259-78.

Rokeach, M. The Open and Closed Mind. N.Y: Basic Books, 1960. 
Samovar, L.A. and Porter, R.E. Intercultural Communication: a Reader. 2nd ed. Belmont: Wadsworth Publishing Co., Inc., 1976.

Sampson, D.I. and Smith, H.P. "A Scale to Measure Worldminded Attitudes." Journal of Social Psychology, 45 (1957), 99-106.

Schuman, H. and Harding, J. "Sympathetic Identification with the Underdog." Public Opinion Quarterly, XXVII (1963), 230-41.

Segall, M.H., et al. The Influence of Culture on Visual Perception. Indianapolis: Bobbs-Merrill Co., 1966.

Shaw, M.E. and Wright, J.M. Scales for the Measurement of Attitudes. N.Y: McGraw-HiII Book Co., 1966.

Sherif, M. The Psychology of Social Norms. N.Y: Harper and Brothers, 1936.

Sherif, M. "The Concept of Reference Groups in Human Relations." Readings in Reference Group Theory and Research. Ed. H.H. Hyman and E. Singer. N.Y: The Free Press, 1968.

Sherif,'M. and Sherif, C. Reference Groups; Explanation into Conformity and Deviation of Adolescents. N.Y: Harper and Row, 1964.

Shibutani, T. "Reference Groups as Perspectives." Readings in Reference Group Theory and Research. Ed. H.H. Hyman and E. Singer. N.Y: The Free Press, 1968

Stagner, R. "Egocentrism, Ethnocentrism, and Altrocentrism: Factors in Individual and Intergroup Violence." International Journal of Intercultural Relations, 1 $(1977), 9-30$.

Stewart, E.C. American Cultural Patterns: a Cross-Cultural Perspective. Society for Intercultural Education, Training and Research, 1972.

Sumner, W.C. Folkways. N.Y: Ginn and Co., 1906.

Swartz, M.J. "Negative Ethnocentrism." Journal of Conflict Resolution, 5 (1961), 75-81.

Taft, R. "Intolerance of Ambiguity and Ethnocentrism." Journal of Consulting Psychology, 20 (1956), 153-54. 
Thomas, D.R. "Authoritarianism, Child-Rearing Practices and Ethnocentrism in Seven Pacific Islands Groups." International Journal of Psychology, 10 (1975), 235-46.

Turner, R. "Role-taking, Role Standpoint and Reference Group Behavior." American Journal of Sociology, 61 (1956), 316-28.

Tzuriel, D. and Klein, N.M. "Ego Identity: Effects of Ethnocentrism, Ethnic Identity, and Cognitive Complexity in Israeli, Oriental and Western Ethnic Groups." Psychological Reports, 40 (1977), 1099-1110.

Urry, J. Reference Groups and the Theory of Revolution. London: Routledge and Kegan Paul, 1973.

Williams, R. Strangers Next Door; Ethnic Relations in American Communities. Englewood Cliffs: Prentice-Hall, 1964.

Williams, T.R. Introduction to Socialization: Human Culture Transmitted. St. Louis: Mosby, 1972.

Zacker, J. "Authoritarian Avoidance of Ambiguity." Psychological Reports, 33 (1973), 901-02. 


\section{APPENDIX A}

\section{THE "WHO ARE YOU?" TEST}

In the blanks below, please write answers to the simple question: "Who are you?". Give as many answers as you can think of. Write the answers in the order that they occur to you. Go along fairly quickly. You will have seven minutes. 
APPENDIX B

THE "ACCEPTANCE/REJECTION OF

OTHER CULTURAL FRAMES

OF REFERENCE" TEST

Please put an ' $X$ ' on the appropriate number for the line corresponding to each question. You will have seven minutes.

1) How would you rate your feeling of how "real" things are?

There is one absolute $\begin{array}{llllllll}1 & 2 & 3 & 4 & 5 & 6 & 7 & \text { There is not one }\end{array}$ reality-it doesn't depend on how we look at things. single realityit depends on how we look at things.

2) How would you rate your feeling of how important the recognition of non-evaluative cultural differences among people is?

It is very important $\begin{array}{llllllll}1 & 2 & 3 & 4 & 5 & 6 & 7 & \text { It is very important }\end{array}$ for world harmony and for world harmony and understanding to recognize that "Under the surface, there are vast. cultural differences among people." understanding to recognize that "Under the surface, there are really no cultural differences among people."

3) How would you rate your feeling of how other cultures' values work for them?

Only certain cultures have values that work well for them.
123345567

All cultures have values that work well for them. 
4) How would you rate your feeling of how similarly people in general perceive the world?

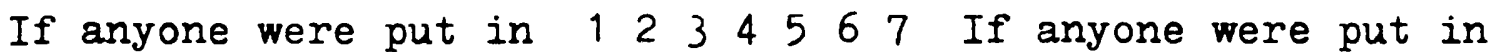
my place, they would see things pretty much the way I do. my place, they would not see things the way I do.

5) How would you rate your feeling of how good other cultures' values are?

Only certain cultures $\begin{array}{llllllll}1 & 2 & 3 & 4 & 5 & 6 & 7 & \text { All cultures provide }\end{array}$ provide their members with a good set of their members with a values. good set of values. 


\section{APPENDIX C}

\section{DIRECTIONS FOR PANEL OF JUDGES}

You are part of a panel of judges. You have before you twenty-one copies of responses to the "Who are you?" test. Your analysis of the respondents' answers is invaluable to the validity and worth of the test. I am going to ask you to make a simple categorization of the responses.

First of all, let's simplify your task even more. Some of the responses will have check marks next to them, some of the responses will not have check marks. Please ignore the ones without check marks. Only the responses that have check marks are of interest to the study. For the responses with check marks after them, your job is to place a ' $C$ ' or an ' $S$ ' next to the response.

A ' $C$ ', or consensual response, is one for which it is easy to decide who would be included in the class or group of people indicated in the response. In other words, it is a cut and dried, or objective, decision. For example, for a response like 'worker', it is relatively easy to recognize what is meant by the response, and to identify those people who would fall under the label 'worker'. Likewise, for a specific kind of worker, like a 'sheet metal worker', or 'factory worker', or 'office worker', it is also obvious what is meant by these kinds of workers, and it is also 
easy to identify who might be included in the group of people indicated in the response. Thus, if you feel that you and most other people could agree upon who would be included in the group or class of people indicated in a response, then please mark that response ' $C$ '.

An 'S', or sub-consensual response, is one for which it is not easy to decide who would be included in the class or group of people indicated in the response. For example, a response like 'hard worker' is a sub-consensual one. It is not that obvious what is meant by the response, nor is it clear just exactly who would be included in a group comprised of 'hard workers'. There is an element of subjectivity on the part of the respondent. Any response that refers to attributes, traits or other matters which would require interpretation by the respondent to be precise is a sub-consensual one. Thus, if you feel that you and most other people could not agree upon who would be included in the group or class of people indicated in a response, then please mark that response ' $\mathrm{S}$ '.

To aid you in making the categorizations, here are some examples of the two types of responses:

$\underline{\mathbf{C}}$

student

from Chicago

girl

oldest child

Baptist

husband

carpenter
$\underline{\mathrm{S}}$

happy person good wife pretty good student

distant son over-weight person

loving husband feminist 
APPENDIX D

\section{GLOSSARY}

ATTITUDE. Positive or negative evaluations, emotional feelings, and pro or con action tendencies with respect to a social object.

AUTHORITARIANISM. Structural rigidity in the personality existing in people who can't tolerate delay of satisfaction of needs.

COMPARATIVE REFERENCE GROUPS. A group which the person uses as a reference point in making evaluations of himself or others.

CONSENSUAL RESPONSE. A reply on the "Who are you?" test which refers to groups and classes whose limits and conditions of membership are matters of common knowledge. CULTURAL IDENTITY. The identity of an individual as he relates to his culture.

DEFENSIVE BEHAVIOR. Behavior which occurs when there is anxiety over the solution of a problem. ENCULTURATION. A means by which people achieve competence in their culture.

ETHNOCENTRISM. A perspective which produces a frame of reference that denies the viability of other cultural frames of reference.

ETHNORELATIVISM. A perspective in which a person has or 
somehow gains awareness of the viability of other cultural frames of reference.

GENERALIZED OTHER. The common impression of all those persons' attitudes that an individual has taken. An individual uses the mechanism that helped him form the generalized other each time he orients himself to a reference group.

INTOLERANCE OF AMBIGUITY. A tendency to adopt an anchoring point quickly in an unstructured situation.

MENTAL RIGIDITY. Inflexible thinking inherent in the solution of non-social and social problems.

NORMATIVE REFERENCE GROUPS. A group whose values, norms and perspective one uses in defining a social situation. PREJUDICE. Negative feelings toward members of other groups.

SUBCONSENSUAL RESPONSE. A reply on the "Who are you?" test which refers to groups, classes, attributes, traits or any other matters which would require interpretation by the respondent to be precise or to place him relative to others. 